\title{
Formic acid above the Jungfraujoch during 1985-2007: observed variability, seasonality, but no long-term background evolution
}

\author{
R. Zander ${ }^{1}$, P. Duchatelet ${ }^{1}$, E. Mahieu ${ }^{1}$, P. Demoulin ${ }^{1}$, G. Roland ${ }^{1}$, C. Servais ${ }^{1}$, J. V. Auwera ${ }^{2}$, A. Perrin ${ }^{3}$, \\ C. P. Rinsland ${ }^{4}$, and P. J. Crutzen ${ }^{5}$ \\ ${ }^{1}$ Institute of Astrophysics and Geophysics, University of Liège, 4000, Liège, Belgium \\ ${ }^{2}$ Service de Chimie Quantique et Photophysique, Université Libre de Bruxelles, 1050, Brussels, Belgium \\ ${ }^{3}$ Laboratoire Interuniversitaire de Systèmes Atmosphériques, CNRS, Université de Paris Est Créteil et Paris 7 , \\ 94010 Créteil cedex, France \\ ${ }^{4}$ NASA Langley Research Center, Hampton, VA 23681-2199, USA \\ ${ }^{5}$ Max Planck Institute for Chemistry, Airchemistry Division, Mainz, Germany
}

Received: 13 April 2010 - Published in Atmos. Chem. Phys. Discuss.: 16 June 2010

Revised: 7 October 2010 - Accepted: 13 October 2010 - Published: 25 October 2010

\begin{abstract}
This paper reports on daytime total vertical column abundances of formic acid $(\mathrm{HCOOH})$ above the Northern mid-latitude, high altitude Jungfraujoch station (Switzerland; $46.5^{\circ} \mathrm{N}, 8.0^{\circ} \mathrm{E}, 3580 \mathrm{~m}$ alt.). The columns were derived from the analysis of infrared solar observations regularly performed with high spectral resolution Fourier transform spectrometers during over 1500 days between September 1985 and September 2007. The investigation was based on the spectrometric fitting of five spectral intervals, one encompassing the $\mathrm{HCOOH} \nu_{6}$ band Q branch at $1105 \mathrm{~cm}^{-1}$, and four additional ones allowing to optimally account for critical temperature-sensitive or time-evolving interferences by other atmospheric gases, in particular $\mathrm{HDO}, \mathrm{CCl}_{2} \mathrm{~F}_{2}$ and $\mathrm{CHClF}_{2}$. The main results derived from the 22 years long database indicate that the free tropospheric burden of $\mathrm{HCOOH}$ above the Jungfraujoch undergoes important shortterm daytime variability, diurnal and seasonal modulations, inter-annual anomalies, but no significant long-term background change.

A major progress in the remote determination of the atmospheric $\mathrm{HCOOH}$ columns reported here has resulted from the adoption of new, improved absolute spectral line intensities for the infrared $v_{6}$ band of trans-formic acid, resulting in retrieved free tropospheric loadings being about a factor two smaller than if derived with previous spectroscopic parameters. Implications of this significant change with regard to earlier remote measurements of atmospheric formic acid
\end{abstract}

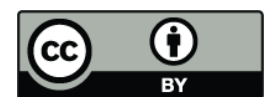

Correspondence to: P. Duchatelet (p.duchatelet@ulg.ac.be) and comparison with relevant Northern mid-latitude findings, both in situ and remote, will be assessed critically. Sparse $\mathrm{HCOOH}$ model predictions will also be evoked and assessed with respect to findings reported here.

\section{Introduction}

Numerous field investigations of volatile organic compounds in the boundary layer and through the free troposphere have been undertaken in situ and remotely during isolated, timelimited local as well as regional studies since the mid-1980s (e.g., local ground-based background monitoring; measurements during natural and controlled savannah fires; related Atlantic and Pacific ship- and airborne campaigns; stratospheric balloon flights- and space-based solar observations). They indicate that $\mathrm{HCOOH}$ is, after acetic acid $\left(\mathrm{CH}_{3} \mathrm{COOH}\right)$, the most abundant global organic carboxylic acid present in the Earth's atmosphere, in both gaseous and liquid phases (e.g., Talbot et al., 1988, 1990; Puxbaum et al., 1988; Andreae et al., 1988; Arlander et al., 1990; Klemm et al., 1994; Sanhueza et al., 1996; Kesselmeier and Staudt, 1999; Khare et al., 1999; Poisson et al., 2000; Legrand et al., 2003, 2004). These studies further suggest that the main $\mathrm{HCOOH}$ sources are of biogenic origin (e.g., direct emissions and indirect production via oxidation and ozonolysis of reactive hydrocarbons released by soils, vegetation, forests, seas, biomass burning, ants) and anthropogenic releases (via wild bush and waste fires, domestic heating, road traffic, ...). The dominant atmospheric $\mathrm{HCOOH}$ removal occurs through dry and wet deposition, thus contributing along with sulfuric, nitric,

Published by Copernicus Publications on behalf of the European Geosciences Union. 
acetic and hydrochloric acids to the acidity in the boundary layer, out to far remote areas. Measurement techniques used in the above researches, as well as formic acid photochemistry modeling calculations have been evoked, e.g., by Keene et al. (1989), Pszenny et al. (1989), Reiner et al. (1999), Poisson et al. (2000), Baboukas et al. (2000), von Kuhlmann et al. (2003), Christian et al. (2004), Rinsland et al. (2004, 2006), Remedios et al. (2007). Despite original findings acquired along these field investigations and related chemical studies in the laboratory, there remain numerous gaps in the observational datasets, preventing regional and global background emissions to be satisfactorily quantified and understood, thus difficult to be adequately modeled.

Observed short-term variability of atmospheric $\mathrm{HCOOH}$ during many field campaigns has led to estimates of its atmospheric lifetime, ranging from hours in the boundary layer to days in the upper troposphere (e.g., Keene and Galloway, 1988; Hartmann et al., 1991; Hahn et al., 1992; Chebbi and Carlier, 1996). Causes for this variability include heterogeneity in the distribution and release intensities of the sources - both biogenic and anthropogenic - at the ground. The latter depend on local/regional vegetation types, orography, and diurnally and seasonally varying environmental conditions such as solar insolation, atmospheric circulation-, temperature- and moisture fields, which also affect dry and wet deposition. Despite time-limited field campaigns, some evidence for diurnal as well as seasonal variations also emerged (e.g., Arlander et al., 1990; Talbot et al., 1988, 1995; Khwaja, 1995; Kajii et al., 1997; Baboukas et al., 2000; Legrand et al., 2004). The combined short lifetime and the location of the main sources at the ground preclude a $\mathrm{HCOOH}$ distribution versus altitude with a small scaleheight through the free troposphere.

Within this introductory context, two relevant reviews ought to be highlighted, namely (i) a comprehensive overview of the fate of biogenic volatile organic compounds in the atmosphere (including $\mathrm{HCOOH}$ ) by Kesselmeier and Staudt (1999), and (ii) a more specific overview by Khare et al. (1999) on the state of measurements of atmospheric formic and acetic acids in the boundary layer and likely interpretations.

In this paper, we provide further evidence of short-term daytime and day-to-day variability, and evaluate diurnal and seasonal modulations, inter-annual variations, as well as the long-term trend of free tropospheric $\mathrm{HCOOH}$ above the highaltitude International Scientific Station of the Jungfraujoch (Switzerland; $46.5^{\circ} \mathrm{N}, 8.0^{\circ} \mathrm{E}, 3580 \mathrm{~m}$ altitude). The findings are based on the spectrometric analysis of solar spectra regularly recorded since the mid-1980s with modern Fourier transform infra-red (FTIR) spectrometers. As in most infrared remote sensing investigations (e.g., Goldman et al., 1984; Shephard et al., 2003; Rinsland et al., 2004, 2006, 2007; Remedios et al., 2007; González Abad et al., 2009; Grutter et al., 2010), the present analysis focuses on the $v_{6}$ band Q branch of $\mathrm{HCOOH}$ near $1105 \mathrm{~cm}^{-1}$, which is by far the most appropriate absorption feature for studying its atmospheric concentration through ground-, airborneand space-based observations. Here however, and as was done in the two last referenced investigations, we adopted a new, improved set of spectroscopic parameters for this $\mathrm{HCOOH} v_{6}$ band, recently released by Perrin and Vander Auwera (2007), and now implemented in the HITRAN-2008 line parameter compilation (Rothman et al., 2009; see also http://www.hitran.com). This new set returns formic acid loadings being about a factor two lower than if derived with parameters found in earlier HITRAN versions (i.e., Rothman et al., 2003, 2005).

\section{Observational database and ancillary inputs}

The database analyzed here is a subset of all solar observations made between 2 and $15 \mu \mathrm{m}$ (about 5000 to $650 \mathrm{~cm}^{-1}$ ) with two Fourier transform spectrometers (FTS) operated at the Jungfraujoch under typical spectral resolutions of 0.003 to $0.006 \mathrm{~cm}^{-1}$ (corresponding to maximum optical path differences of 165 and $82 \mathrm{~cm}$, respectively), allowing to study quasi-simultaneously over two dozen atmospheric gases (Zander et al., 2005, 2008). The retained subset contains 8256 individual spectra recorded during 1537 days between September 1985 and September 2007 with an optical filter specifically covering the 700 to $1400 \mathrm{~cm}^{-1}$ spectral domain, thus encompassing the $\mathrm{HCOOH} v_{6}$ band Q branch at $1105 \mathrm{~cm}^{-1}$. These spectra were all acquired at solar zenith angles (SZA) $<87^{\circ}$, a geometry mitigating targetversus interfering gas absorptions in near-horizontal observations. Notice that the mountainous orography around the Jungfraujoch station prevents this SZA limit to be reached during some periods of the year, either at sunrise or at sunset. Until March 1995, the observations were predominantly made with a home-built FTS (Delbouille and Roland, 1995), while a faster commercial Bruker-Type120 HR FTS was used more consistently onwards. The signal-to-noise $(\mathrm{S} / \mathrm{N})$ ratio varied from about 300 (essentially earlier single recordings) to over 2500 (corresponding to "average" spectra, resulting from individual Bruker scans obtained during time intervals of 6 to $30 \mathrm{~min}$, depending on the solar zenith angle rate of change). Near-coincident $\mathrm{HCOOH}$ measurements with both instruments were specifically inter-compared to assess the consistency of the data retrieved with either instrument.

The model atmosphere adopted above the $3.58 \mathrm{~km}$ Jungfraujoch site to compute synthetic spectra for comparison with the observed ones (see Sect. 4) consisted of 41 layers: the two lower ones were successively 0.32 and $0.70 \mathrm{~km}$ thick, followed higher up by 24 layers equally spaced by $1.2 \mathrm{~km}$, and additional ones progressively increasing in thickness to reach $100 \mathrm{~km}$ altitude. The mean physical pressuretemperature characteristics of these layers were derived from midday pressure-temperature profiles, specifically calculated for the location of the Jungfraujoch by the US-National 
Centers for Environmental Prediction (NCEP, Washington, DC; see http://www.ncep.noaa.gov). The "a priori" volume mixing ratio (VMR) profile adopted for retrieving the $\mathrm{HCOOH}$ target gas decreases quasi-monotonically through the free troposphere above the site (i.e., 440, 300, 190, 100 pptv (parts per trillion or $10^{-12}$ by volume), respectively at $3.58,6.0,8.5$, and $11 \mathrm{~km}$ altitude, and set to zero at $17 \mathrm{~km}$ and above). The slope of this a priori profile is commensurate with the altitude-dependent characteristics derived by Reiner et al. (1999) from in situ measurements of $\mathrm{HCOOH}$ between $7 \mathrm{~km}(215 \mathrm{pptv})$ and $11.3 \mathrm{~km}$ (59 pptv) altitude made in the fall of 1991 during five airplane flights above Southern Germany, only a few latitudinal degrees north of the Jungfraujoch. Supporting $\mathrm{HCOOH}$ concentration decreases versus altitude at Northern mid-latitudes have also been reported by Talbot et al. (1996a, b, 1997a, b) and by Singh et al. (2000) during airborne missions, respectively over the Northern Pacific and Atlantic oceans. The adopted slope is further in line with vertical transport investigations based on tropospheric measurements of ${ }^{222}$ Radon (lifetime of 5.5 days) distributions at Northern mid-latitudes (e.g., Nazarov et al., 1970; Liu et al., 1984). Validation of the adopted $\mathrm{HCOOH}$ profile in the upper troposphere and up through the lower stratosphere was assessed by one of us (P. Du) and more recently confirmed by González Abad et al. (2009), based on solar occultation measurements at Northern mid-latitudes with the ACE (Atmospheric Chemistry Experiment) FTS aboard the Canadian SCISAT satellite (Bernath et al., 2005). A priori VMR profiles for major interfering gases were compiled from reliable sets of space - (i.e., ATMOS (Atmospheric Trace Molecule Spectroscopy; Irion et al., 2002); HALOE (Halogen Experiment; http://haloe.gats-inc.com); ACE) and stratospheric balloon - based in situ measurements at Northern mid-latitudes (i.e., A. Engel, Goethe University of Frankfurt, private communication, 2004).

\section{New $\mathrm{HCOOH} v_{6}$ band intensity}

The first tentative identification of formic acid in the upper troposphere was reported by Goldman et al. (1984), based on solar spectra recorded from aboard a stratospheric balloon platform above Arizona (USA). They used $\mathrm{HCOOH} v_{6}$ band parameters derived by Goldman and Gillis (1984) from the analysis of a laboratory spectrum whose total $\mathrm{HCOOH}$ line intensities over the $1000-1200 \mathrm{~cm}^{-1}$ interval corresponded to $19.96 \times 10^{-18} \mathrm{~cm}^{-1} /\left(\right.$ molec $\left.\mathrm{cm}^{-2}\right)$ at $296 \mathrm{~K}$. Assuming this band intensity, Perrin et al. (1999) undertook a theoretical Hamiltonian analysis of the fundamental $v_{6}$ and the interacting $v_{8}$ bands of $\mathrm{HCOOH}$. They generated a detailed set of line positions and intensities, which significantly improved the quality of fits to observed $\mathrm{HCOOH}$ spectra. This set of lines was incorporated in the HITRAN-2004 compilation (Rothman et al., 2005).
Meanwhile, Vander Auwera et al. (2004) raised a concern, namely the fact that several independent spectroscopic studies, both laboratory as well as theoretical, had reported integrated intensities of the $\mathrm{HCOOH} v_{6}$ band that were higher than the Goldman and Gillis (1984) value by about a factor of 2 (see Table V in Vander Auwera et al., 2007). Using new $\mathrm{HCOOH}$ laboratory spectra recorded between 600 and $1900 \mathrm{~cm}^{-1}$ with a high resolution $\left(0.002 \mathrm{~cm}^{-1}\right)$ Fourier transform spectrometer, at various total sample pressures ranging from 14.3 to $314 \mathrm{~Pa}$, they measured the absolute intensity of 72 lines in the $v_{6}$ band, with an absolute uncertainty estimated to be at most $7 \%$, and performed a detailed Hamiltonian analysis of $v_{6} / v_{8}$ interacting bands. Specifics of the approach - both experimental and analytical - as well as emerging issues can be found in Vander Auwera et al. (2007). In particular, an integrated $\mathrm{HCOOH}$ band intensity over the $1045-1150 \mathrm{~cm}^{-1}$ interval was found equal to $38.8 \times 10^{-18} \mathrm{~cm}^{-1} /\left(\right.$ molec $\left.\mathrm{cm}^{-2}\right)$ at $296 \mathrm{~K}$, thus nearly twice the value reported by Goldman and Gillis (1984). Perrin and Vander Auwera (2007) synthesized the original improvements of this research with respect to earlier ones, pointing out that the new band intensity refers to the trans- form of $\mathrm{HCOOH}$, as natural formic acid only contains about $0.1 \%$ of the $\mathrm{HCOOH}$ cis-form (Hocking, 1976). They further compiled an improved line list for fitting $\mathrm{HCOOH}$ in the 9-micron region, containing individual positions and intensities of almost 50000 lines between 940.20 and $1244.41 \mathrm{~cm}^{-1}$. All air-broadening line half-widths were set to $0.101 \mathrm{~cm}^{-1} \mathrm{~atm}^{-1}$ at $296 \mathrm{~K}$ (a value assessed experimentally by Notholt et al., 1991), with a temperature dependence exponent $n=0.75$, and a self-broadening parameter $\gamma=0.32 \mathrm{~cm}^{-1} \mathrm{~atm}^{-1}$ at $296 \mathrm{~K}$ derived in Vander Auwera et al. (2007). This new HCOOH database, merged with the line parameters of the HITRAN-2004 compilation for all other atmospheric molecules, has been used here prior to publication. At the time of this writing it has been formally incorporated in the most recent HITRAN-2008 compilation (Rothman et al., 2009), thus available to the scientific community. The factor 2 needs to be kept in mind when relating the $\mathrm{HCOOH}$ results reported here with earlier infrared remote sensing findings, e.g., by Goldman et al. (1984), Shephard et al. (2003), Rinsland et al. (2004, 2006 and 2007), Remedios et al. (2007), some of which will be discussed in Sect. 6 and in Appendix A. Incidentally, this factor 2 also explains the discrepancy observed by Christian et al. (2004) when intercomparing $\mathrm{HCOOH}$ emissions of biomass-burning material conducted in the laboratory, simultaneously with a proton transfer reaction-mass spectrometer (PTR-MS) and an open path-Fourier transform infrared (OP-FTIR) instrument. The OP-FTIR findings were consistently about twice larger than those derived with the PTR-MS technique; with the new parameters, the results would have been comparable. 


\section{Spectrometric analysis approach}

The analysis of the 8256 solar spectra retained here was performed with the SFIT2 retrieval algorithm, using the spectroscopic parameters compiled by Perrin and Vander Auwera (2007) evoked in Sect. 3. The main features of the SFIT2 code have been described by Pougatchev et al. (1995) and by Rinsland et al. (1998). It incorporates a semi-empirical implementation approach of the optimal estimation formalism developed by Rodgers (1976), as well as an error evaluation discussed by Connor et al. (1995). The SFIT2 Version 3.91 used here specifically allows to simultaneously (i) derive information on the VMR variation versus altitude of up to 3 target gases, (ii) uniformly scale the a priori profiles of up to 8 interfering gases, and (iii) further deal with the absorption characteristics of up to 50 other ones according to prescribed, most realistic VMR profiles.

In order to properly account for a critical interference by a temperature-sensitive HDO line at $1104.8759 \mathrm{~cm}^{-1}$ $\left(\mathrm{E}^{\prime \prime}=701.6 \mathrm{~cm}^{-1}\right.$; a concern already stressed by Perrin et al., 1999), as well as time evolving continuum-type absorptions by $\mathrm{CCl}_{2} \mathrm{~F}_{2}$ and $\mathrm{CHClF}_{2}$ (e.g., Meier et al., 2004), a variant of the simultaneous multiple-windows approach used by Rinsland et al. (2004) was adopted here. In a first run, four preselected micro-windows were fitted together in each retained spectrum, namely two for HDO $\left(1206.18\right.$ to $1206.67 \mathrm{~cm}^{-1}$ and 1208.58 to $1208.98 \mathrm{~cm}^{-1}$; lines with $\mathrm{E}^{\prime \prime}=683.5 \mathrm{~cm}^{-1}$, thus very close to the temperature dependence of the interfering HDO line), one for $\mathrm{CCl}_{2} \mathrm{~F}_{2}\left(922.50\right.$ to $\left.923.60 \mathrm{~cm}^{-1}\right)$ and one for $\mathrm{CHClF}_{2}\left(828.85\right.$ to $\left.829.25 \mathrm{~cm}^{-1}\right)$ by scaling their a priori VMR profiles. These spectrum-specific retrieved profiles were then used as such in a second fitting run encompassing the 1104.65 to $1105.60 \mathrm{~cm}^{-1}$ interval, in which the distribution of the two most important interfering $\mathrm{O}_{3}$ isotopomers $\left({ }^{16} \mathrm{O}_{3}\right.$ and $\left.{ }^{16} \mathrm{O}^{16} \mathrm{O}^{18} \mathrm{O}\right)$ were retrieved, while the a priori VMR profile of $\mathrm{HCOOH}$ characterized in Sect. 2 was uniformly scaled over its entire altitude span. This simple scaling was justified, considering the poor spectroscopic pressure/temperature information content that can be exploited along fittings to Q-branches containing hundreds of weak overlapping lines. Additional discrete absorptions by gases such as $\mathrm{H}_{2} \mathrm{O}, \mathrm{CH}_{4}, \mathrm{CO}_{2}$ and $\mathrm{N}_{2} \mathrm{O}$ were also accounted for in both runs by scaling assigned, most realistic VMR profiles. A signal-to-noise ratio of 500 was set in all fitting sequences, commensurate with the noise level of most analyzed spectra. Inspection of extra-atmospheric solar observations by the shuttle-based ATMOS-FTIR instrument (Farmer and Norton, 1989) showed that no solar lines perturb any of the 5 spectral intervals used here.

Frame B of Fig. 1 reproduces a fit to a typical spectrum observed at the Jungfraujoch on 8 June 2005, with residuals (Frame C) resulting from the combined absorption characteristics of the six most important gases identified in Frame A, as well as contributions from second order ones listed in the previous paragraph. Individual inspection of the fittings

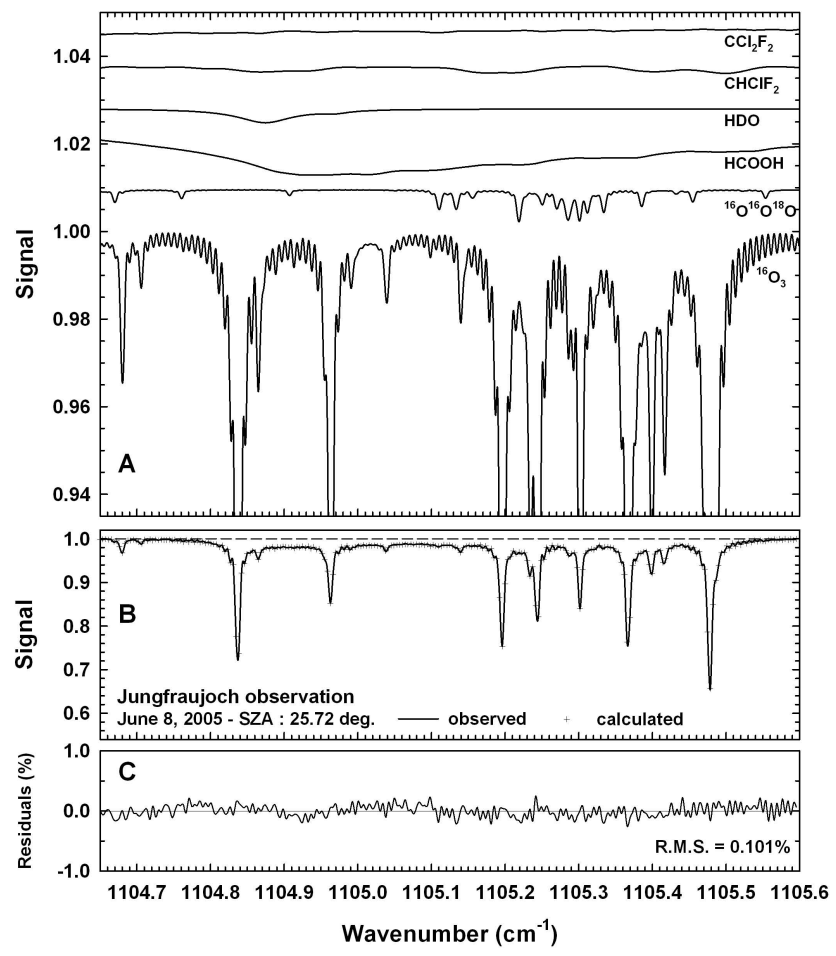

Fig. 1. Typical fitting example to an observed spectrum (respectively crosses and continuous line in Frame (B) extending from 1104.65 to $1105.60 \mathrm{~cm}^{-1}$, recorded at the Jungfraujoch on 8 June 2005 , with a spectral resolution of $0.004 \mathrm{~cm}^{-1}$. The resulting residuals (observed minus calculated signals) are displayed in Frame (C), with a corresponding root mean squares fitting residual equal to $0.101 \%$, which is consistent with the displayed spectrum's $\mathrm{S} / \mathrm{N}$ ratio of 1285 . Frame (A) shows the individual discrete absorption characteristics (shifted vertically for clarity) of the $\mathrm{HCOOH}$ target gas and the 5 most important interfering ones which, complemented by contributions from other second order interfering gases, correspond to the fit in Frame B.

to all analyzed spectra led to rejecting 616 of them, based on objective criteria such as local fringing, no fitting convergence, excessive root-mean square fitting residuals with respect to the spectral $\mathrm{S} / \mathrm{N}$ ratio, and all $\mathrm{HCOOH}$ columns falling in the $\times 10^{13} \mathrm{molec} / \mathrm{cm}^{2}$ range (most of which showed fitting uncertainties near or exceeding the retrieved columns). The $1 \times 10^{14} \mathrm{molec} / \mathrm{cm}^{2}$ level which was established through spectroscopic calculations as being a reasonable sensitivity limit for our $\mathrm{HCOOH}$ retrieval approach may, however, introduce a slight positive bias which will be estimated in the next section. The database discussed hereafter thus includes 7640 individual $\mathrm{HCOOH}$ total column measurements encompassing 1501 days. They were normalized to the mean local pressure observed at the Jungfraujoch during the past two decades (i.e. $654 \mathrm{mb}$ ) versus the specific daily NCEPreported pressures. 
Table 1. Impact of major sources of random (R) and systematic (S) uncertainties on typical individual HCOOH column retrievals above the Jungfraujoch.

\begin{tabular}{lccl}
\hline Sources of uncertainty & R or S & Max. Error (\%) & Remarks \\
\hline Spectra quality & $\mathrm{R}$ & 4 & zero offset and S/N \\
Pressure-Temperature profile & $\mathrm{R}$ & 4 & $\pm 4 \mathrm{~K}$ against noon NCEP profile \\
HCOOH a priori profile & $\mathrm{R}$ & 7 & $\pm 50 \%$ variability around a priori \\
HDO a priori profile & $\mathrm{R}$ & 6 & $\pm 50 \%$ variability around a priori \\
Other interferences & $\mathrm{R}$ & 5 & other gases, i.e. $\mathrm{O}_{3}, \mathrm{H}_{2} \mathrm{O}, \mathrm{CHClF}_{2}$ \\
RSS $^{*}$ Total Random & & $<\mathbf{1 3}$ & \\
HCOOH spectroscopy. & $\mathrm{S}$ & $<7$ & band intensity; see Sect. 3 \\
HDO spectroscopy & $\mathrm{S}$ & 6 & HITRAN-2004 \\
$\mathrm{O}_{3}$ spectroscopy & $\mathrm{S}$ & 3 & HITRAN-2004 \\
HCOOH a priori profile & $\mathrm{S}$ & 12 & constant versus sloped profile \\
HDO a priori profile & $\mathrm{S}$ & 8 & factor 2 change in a priori slope \\
ILS and forward model & $\mathrm{S}$ & 5 & retrieval algorithm-related \\
RSS* Total Systematic & & $<\mathbf{1 8}$ & \\
\hline
\end{tabular}

* RSS stands for square root of the sum of the squares.

Key observational and analytical sources of uncertainty are reported in Table 1, showing that the largest errors are linked to the adopted a priori $\mathrm{HCOOH}$ and HDO profiles. For both species, the uncertainties have been split into a random and a systematic component, the former relating more specifically to short-term, altitude-dependent variability, and the latter to an overall uncertainty, e.g., the mean slope of the profiles. This distinction is worth being made, considering that the root square sum of the total random errors refers to individual $\mathrm{HCOOH}$ retrievals, thus reducing by the square root of the number of measurements intervening in averaged spectra as well as in daily and monthly mean column loadings. The reported uncertainties result from evaluations or simulations according to specifics given in the last column of Table 1. Overall, they are commensurate with those reported in similar researches by Rinsland et al. (2004) and by Remedios et al. (2007) which are evoked in Appendix A. One exception however, namely the new $\mathrm{HCOOH}$ spectroscopic $v_{6}$ band intensity adopted here being only affected by a systematic uncertainty of less than 7\% (Vander Auwera and Perrin, 2007), as compared to $12 \%$ for the older band intensity used by Rinsland et al. (2004) and by Remedios et al. (2007), both of which are further affected by the systematic factor 2 discussed in Sect. 3.

\section{Results}

The retained individual pressure-normalized $\mathrm{HCOOH}$ column abundances are reproduced in Fig. 2a, while Fig. 2b shows the daily arithmetic means and related one-sigma standard deviations resulting from the individual values involved, on average 5 per day, with extremes ranging from 1 to 56 . This wide range of day-to-day $\mathrm{HCOOH}$ observations results from the fact that (1) two dozen atmospheric gases are being monitored at the Jungfraujoch using alternatively one among 4 wide band-pass optical filters encompassing altogether the spectral interval 2 to $15 \mu \mathrm{m}$, and (2) on many days, solar observations are restricted to periods of breaks in partly cloudy skies.

Both frames of Fig. 2 reveal striking features, namely frequent sub-daily and day-to-day variability, as well as a clear seasonal modulation which is definitely characterized by low $\mathrm{HCOOH}$ columns occurring predominantly during the months of November-December-January (abbreviated hereafter by N-D-J; similar abbreviations will be adopted for other month groupings). All N-D-J daily mean columns are identified in Fig. $2 \mathrm{~b}$ by the open circles with central crosses. After discarding some of these "crossed" data points, namely those from November 1991 to January 1995 (slightly biased high due to degradation of the home-made FTIR instrumental line shape, which affects the correct fitting of the strong interfering ozone lines; see Fig. 1) as well as a few abnormally high outliers (i.e., 21 January 1996, 16 November 2006 and 14 January 2007, which exceeded by over a factor 4 all other daily mean columns measured during these months), a linear adjustment to the remaining $269 \mathrm{~N}-\mathrm{D}-\mathrm{J}$ daily mean columns returns a best fit $\mathrm{HCOOH}$ mean daytime "background" value (continuous line in Fig. 2b) and a 1- $\sigma$ standard deviation (dashed lines) of $(0.38 \pm 0.20) \times 10^{15} \mathrm{molec} / \mathrm{cm}^{2}$. This value also applies to Fig. 2 a when considering the individual measurements made during the same retained days). The present database therefore suggests that the N-D-J mean $\mathrm{HCOOH}$ daytime background loading above the Jungfraujoch has not changed statistically during the past two decades. The positive bias resulting from our rejection of columns below the adopted sensitivity level of $1 \times 10^{14} \mathrm{molec} / \mathrm{cm}^{2}$ (see Sect. 4) was calculated to be at most $0.020 \times 10^{15} \mathrm{molec} / \mathrm{cm}^{2}$, thus only about $5 \%$ of the mean N-D-J background value derived 

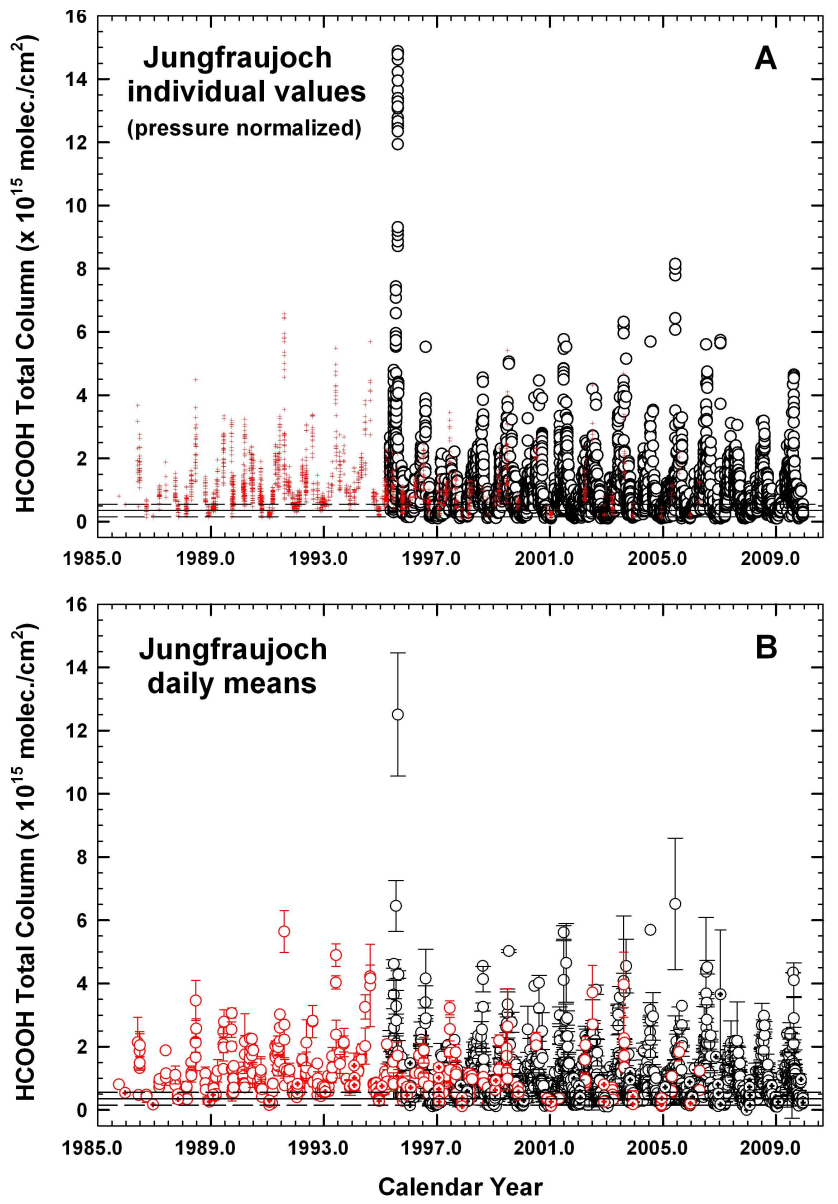

Fig. 2. Frame (A) reproduces all individual total $\mathrm{HCOOH}$ column abundances derived in this work, while Frame (B) shows the daily arithmetic means and their related standard deviations. In both frames, the red and black symbols correspond to columns derived from observations made, respectively with the home-built FTIR spectrometer and with the commercial Bruker-120 HR instrument. In Frame B, the crossed circles identify daily mean columns observed during the November-December-January months, which have been used selectively to determine a "background" mean daytime loading (continuous line) and a standard deviation (dashed lines) of $\mathrm{HCOOH}$ above the Jungfraujoch during that period of the year. For details, see the beginning of Sect. 5 .

here, and well within the associated standard deviation. During the rest of the year, no columns fell below the $1 \times 10^{14} \mathrm{molec} / \mathrm{cm}^{2}$ limit.

The short-term, sub-daily $\mathrm{HCOOH}$ variability can be appreciated by the magnitude of the $1-\sigma$ standard deviation bars in Fig. 2b, with extreme individual values often diverging by over $\pm 50 \%$ around the means. Day-to-day variations of similar magnitude have also been observed frequently, as confirmed by the extent of the standard deviation bars associated to many monthly mean $\mathrm{HCOOH}$ columns displayed on a one-year time base in Fig. 3. A few obvious monthly mean outliers are identified by triangular symbols, namely from left to right for January 2007, June 1993, August 1995, August 1994, and September 1989. The thick curve in Fig. 3 corresponds to a running mean fit to the black filled symbols only, with a 15-day step and a 2-month wide integration time (each step includes between 27 and 43 monthly mean data points). This fit reveals a clear yearly modulation of the mean daytime $\mathrm{HCOOH}$ loading, with a broad maximum during June-July-August (J-J-A) averaging $1.70 \pm 0.50 \times 10^{15} \mathrm{molec} / \mathrm{cm}^{2}$, and a minimum of $0.42 \pm 0.18 \times 10^{15} \mathrm{molec} / \mathrm{cm}^{2}$ (thin continuous line) for all N-D-J data, which is commensurate with the more selective value derived in Fig. 2. The shaded area visualizes the 1$\sigma$ standard deviation associated to the running mean curve and reflects primarily the inter-annual variability noticeable in Fig. 2. If, as suggested by Talbot et al. (1997a), we consider as "enhancement" those $\mathrm{HCOOH}$ columns exceeding the N-D-J background level plus twice its standard deviation (thin dashed line in Fig. 3), then the observed columns from about mid-April to the end of August indicate a statistically significant seasonal modulation at the one sigma level.

To allow some comparisons of our total $\mathrm{HCOOH}$ column measurements with other findings frequently reported as local mole fractions, we have reproduced on the right side of Fig. 3 a scale that allows converting an observed total $\mathrm{HCOOH}$ column abundance read off the left side scale of Fig. 3 into a mean VMR concentration (expressed in pptv) over the 3.58 to $10.6 \mathrm{~km}$ altitude range. It was determined by ratioing the total number of $\mathrm{HCOOH}$ molecules derived over that altitude interval against the total air molecules over the same range. The upper $10.6 \mathrm{~km}$ limit of the range corresponds to the top height of the 7th layer of the adopted model atmosphere (see Sect. 2), which is nearest to the mean tropopause height $(\sim 11.3 \mathrm{~km})$ above the Jungfraujoch during the past two decades. Notice that the conversion from $\mathrm{HCOOH}$ columns to mean VMRs carries the systematic uncertainties reported in Table 1.

Table 2 lists the arithmetic monthly mean $\mathrm{HCOOH}$ daytime columns and corresponding mean VMRs, as well as their relative uncertainties and number of years involved in each monthly mean, derived from the filled data points of Fig. 3. They are commensurate with the 2-month wide running means reproduced by the thick curve in that figure. At the one-sigma level, they can be considered as representative of the month-specific climatology of the total columns and mean free tropospheric VMRs of $\mathrm{HCOOH}$ above the Jungfraujoch from mid-1987 to mid-2007, returning a maximum in July and a minimum in December. The mean annual loading for that period is provided in the last row of Table 2 .

Attention has also concerned the $\mathrm{HCOOH}$ diurnal variation above the Jungfraujoch. This is illustrated in Fig. 4, which displays all the individual vertical columns versus solar zenith angle derived from observations made with the Bruker instrument between 1995 and 2007, i.e., all open black circles of Fig. 2a (a total of 5158 data points gathered during 1219 days). Only the Bruker data were considered 


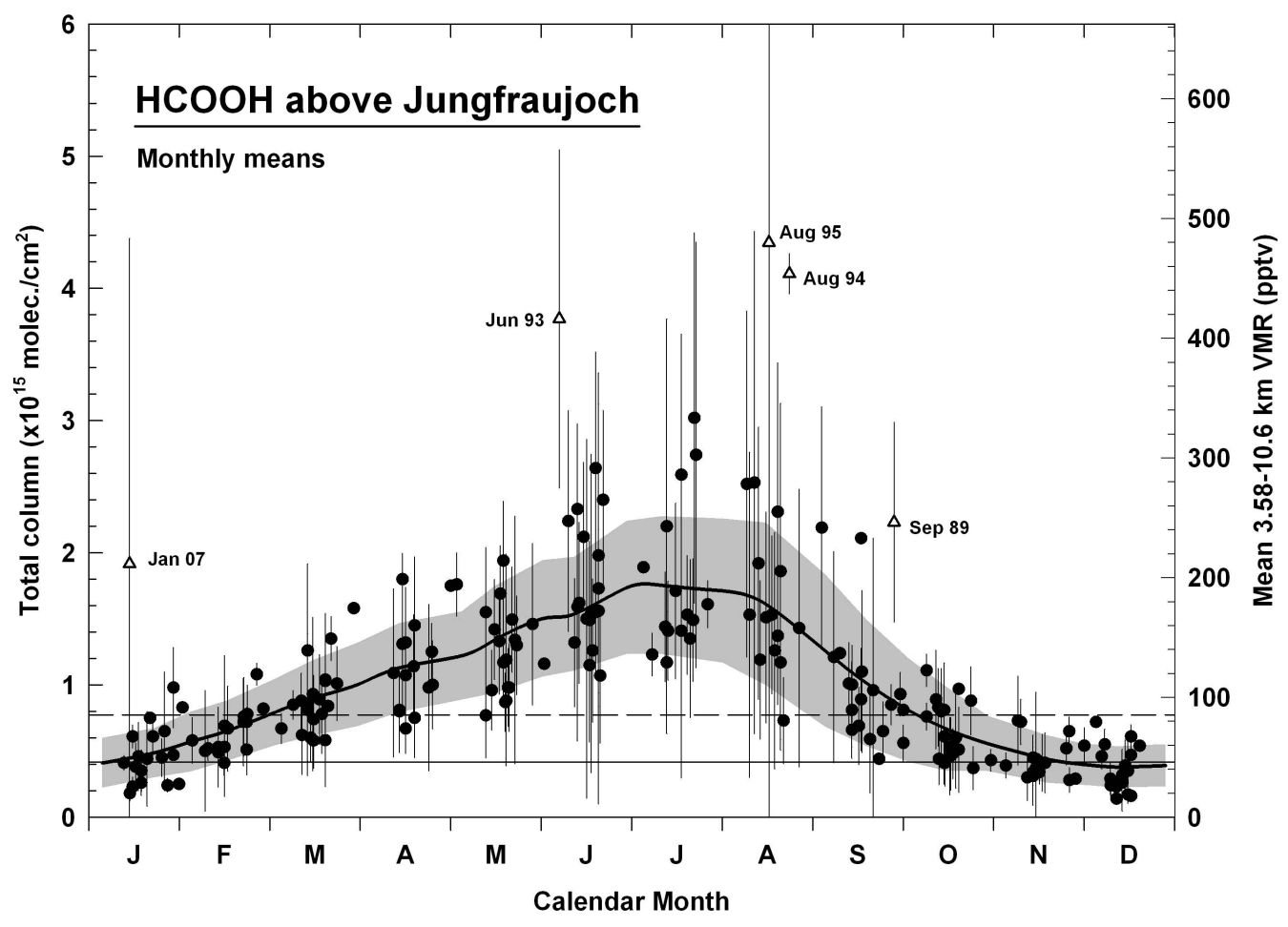

Fig. 3. Monthly mean column abundances and associated standard deviation bars displayed on a one-year time base, with 5 obvious monthly mean outliers identified by triangular symbols. The thick curve corresponds to a running mean fit to the black filled symbols only, with a 15day step and a 2-month wide integration time. The shaded area visualizes the $1-\sigma$ standard deviation associated to the running mean curve and reflects primarily the observed inter-annual variability noticeable in Fig. 2. The dashed line, which corresponds to the mean HCOOH loading of November-December-January (thin continuous line) plus twice its standard deviation, visualizes the presence of a seasonal modulation in the 1985-2007 database. The right side scale allows converting an observed total HCOOH column abundance read off the left side scale into a mean VMR concentration (expressed in parts per trillion by volume, i.e., pptv) over the 3.58 to $10.6 \mathrm{~km}$ altitude range. For details on this conversion, see Sect. 5, Paragraph 4.

Table 2. Month-specific climatology of the mean daytime $\mathrm{HCOOH}$ loading above the Jungfraujoch for the 1985 to 2007 period.

\begin{tabular}{lrrrr}
\hline $\begin{array}{l}\text { Month }+ \\
\text { Annual Mean }\end{array}$ & $\begin{array}{r}\text { Nr. of } \\
\text { Years }\end{array}$ & $\begin{array}{r}\text { Mean Col. } \\
\times 10^{15} \\
\text { molec/cm }\end{array}$ & $\begin{array}{r}\text { Mean VMR } \\
\text { in pptv }\end{array}$ & $\begin{array}{r}\text { Std. Dev. } \\
\text { in \% }\end{array}$ \\
\hline January & 17 & 0.455 & 50.1 & 46.7 \\
February & 18 & 0.679 & 74.7 & 28.5 \\
March & 20 & 0.895 & 98.5 & 29.4 \\
April & 15 & 1.146 & 126.0 & 29.8 \\
May & 18 & 1.283 & 141.1 & 26.0 \\
June & 19 & 1.697 & 186.7 & 27.1 \\
July & 15 & 1.785 & 196.4 & 32.7 \\
August & 14 & 1.632 & 179.5 & 32.8 \\
September & 19 & 0.983 & 108.1 & 47.2 \\
October & 20 & 0.639 & 70.3 & 34.6 \\
November & 17 & 0.441 & 48.1 & 32.8 \\
December & 18 & 0.360 & 39.6 & 46.1 \\
\hline Annual Mean & 17.5 & 1.01 & 110.9 & 34.4 \\
\hline
\end{tabular}

here, owing to their overall improved temporal regularity. Because of the large short-term variability superimposed on seasonal and inter-annual modulations, a vertical logarithmic scale was adopted to better appraise lower column loadings. While there is indication of an overall qualitative sunrise to sunset total $\mathrm{HCOOH}$ column modulation peaking around mid-day, a more quantitative assessment requires evaluating specific data subsets, as solar culmination occurs at heights varying over the year. This is highlighted in Fig. 4, where the filled cyan circles correspond to all N-D-J data points, with solar culmination occurring at about $62^{\circ}$ zenith angle. First order fittings, separately to the AM and PM cyan points are reproduced by the continuous yellow lines. Extrapolated to $90^{\circ} \mathrm{SZA}$ to the left for "sunrise" and to the right for "sunset", they show that the mean N-D-J loading of $\mathrm{HCOOH}$ above the Jungfraujoch increases by a factor 2 , from $0.26 \times 10^{15} \mathrm{molec} / \mathrm{cm}^{2}$ at sunrise to $0.49 \times 10^{15} \mathrm{molec} / \mathrm{cm}^{2}$ at culmination, then decreases towards $0.30 \times 10^{15} \mathrm{molec} / \mathrm{cm}^{2}$ at sunset. The black lines correspond to similar AM and PM fittings to all J-J-A data points, while the red lines refer to all May data points 


\section{Bruker individual data (1995-2009)}
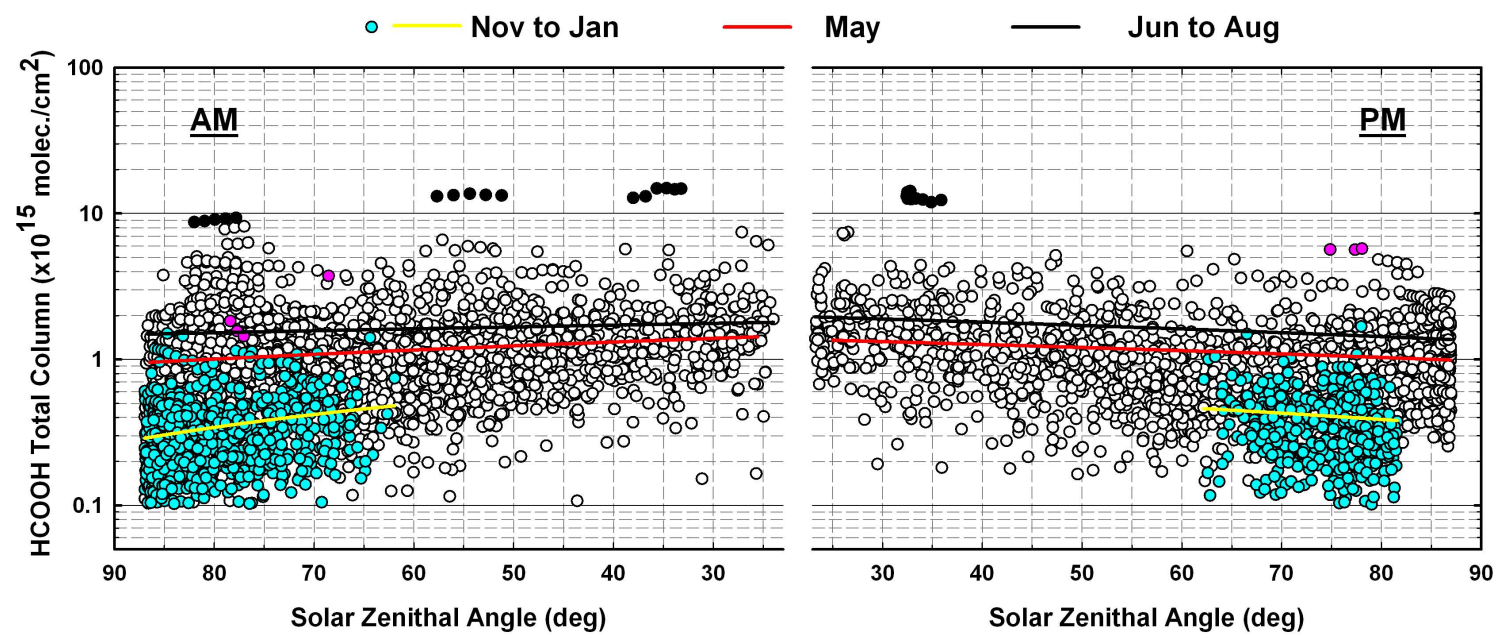

Fig. 4. Illustration of the diurnal variation of $\mathrm{HCOOH}$ above the Jungfraujoch, based on the individual Bruker FTIR observations between 1995 and 2007, with overall AM increases and PM decreases evaluated separately. First order fittings to all N-D-J data (filled cyan points) are highlighted by the two yellow lines. The black and red lines correspond to similar fittings, respectively to all J-J-A and May observations. Related AM increases and PM decreases are given in Table 3 The extreme high HCOOH columns observed on 15 August 1995 and on 14 January 2007 (respectively 25 black and 7 pink filled circles) were excluded from the fittings.

only (featured for a comparison with Mauna Loa observations discussed in Appendix A). The statistical significance of the mean AM increases and PM decreases for the 3 pairs of lines displayed in Fig. 4 was established by application of the bootstrap resampling method described by Gardiner et al. (2008). During the morning, the column increases (expressed in $\times 10^{13} \mathrm{molec} / \mathrm{cm}^{2}$ per degree of zenith angle change) and their 2-sigma uncertainties were found equal to $(+0.81 \pm 0.25),(+0.79 \pm 0.34)$ and $(+1.24 \pm 0.49)$, respectively for N-D-J, May, and J-J-A. The corresponding PM decreases were equal to $(-0.67 \pm 0.41),(-0.66 \pm 0.43)$ and $(-1.34 \pm 0.52)$. All these examples show that the diurnal modulation of the free tropospheric $\mathrm{HCOOH}$ loading is statistically significant, despite the high short-term variability characterizing the overall present database. The relative uncertainty in the PM decreases is, however, somewhat larger than that for the AM increases, resulting from the fact that less observations are made in the afternoon due to frequent high cirrus clouds occurrences, and/or sun occultations at solar zenith angles larger than $\sim 81^{\circ}$ due to the mountainous orography around the site (i.e., see the bottom right part of Fig. 4). The simple evaluation here of AM increases and PM decreases, with solar culmination around noontime, includes frequent situations when $\mathrm{HCOOH}$ column maxima were observed during late morning or early afternoon. Specific first order AM increases and PM decreases for various monthgroupings are provided in Table 3 .

\section{Discussion}

All observational field campaigns referred to in this paper consistently report large short-term variability of atmospheric $\mathrm{HCOOH}$ either in ground-, sea- or airborne based in situ air samplings, as well as in slant column remote-sensing spectrometric observations from the ground or from space. Likely causes include regional sources diversity and strength variations as well as specific meteorological conditions affecting local emissions and dry/wet deposition evoked in the introductory section. In this context, Fig. 2 shows that the Jungfraujoch $\mathrm{HCOOH}$ database makes no exception, despite the fact that, with respect to local in situ concentration measurements, short-term variability is further smoothed in spectrometric remote sensing observations, as they integrate information over long optical slant paths through the atmosphere.

The difficulty of identifying prevailing processes responsible for observed variability of short lifetime trace constituents (gases as well as aerosols) in a complex mountainous terrain such as the surrounding Jungfraujoch area has been documented and discussed by Baltensperger et al. (1997) and Forrer et al. (2000). These authors stressed the key role of local thermal convection during spring and summer, resulting in upslope winds that carry gases and aerosols from boundary layer valleys and catchment slopes to the Jungfraujoch site and higher up. This enhanced thermal effect, combined with the increasing agricultural soil treatment activity and natural biogenic vegetation 
Table 3. Mean AM increases and PM decreases of the HCOOH loading above the Jungfraujoch based on the 1995-2007 observations with the Bruker instrument.

\begin{tabular}{|c|c|c|c|c|c|}
\hline \multirow[t]{2}{*}{ Months } & \multicolumn{5}{|c|}{ All columns in $\times 10^{15} \mathrm{molec} / \mathrm{cm}^{2}-$ in brackets, related mean VMRs in pptv } \\
\hline & "Sunrise" & $\leftarrow$ Increase $\rightarrow$ & Culmination & $\leftarrow$ Decrease $\rightarrow$ & "Sunset" \\
\hline Nov-Dec-Jan & $0.26[29]$ & $0.23[25]$ & $0.49[55]$ & $0.19[21]$ & $0.30[33]$ \\
\hline Feb-Mar & $0.58[64]$ & $0.20[22]$ & $0.78[86]$ & $-0.09[-10]$ & $0.87^{1}[96]$ \\
\hline Apr-May & $0.90[99]$ & $0.39[43]$ & $1.29[142]$ & $0.34[37]$ & $0.95[105]$ \\
\hline Jun-Jul-Aug & $1.50[165]$ & $0.50[55]$ & $2.00[220]$ & 0.65 [72] & 1.35 [148] \\
\hline Sep-Oct & $0.50[55]$ & $0.40[44]$ & 0.90 [99] & 0.13 [14] & 0.77 [85] \\
\hline Year Mean & $0.77[85]$ & $0.35[38]$ & 1.12 [123] & 0.29 [35] & $0.83^{1}[91]$ \\
\hline May only & $0.94[103]$ & $0.48[53]$ & 1.42 [156] & $0.45[48]$ & 0.97 [107] \\
\hline
\end{tabular}

${ }^{1}$ the Feb-Mar sunset value is significantly biased high due to low density of data points and missing low sun observations evoked in Sect. 2 (see bottom right part of Fig. 4 ) ; it has, therefore been excluded from the yearly mean.

metabolisms (e.g., Kesselmeier and Staudt, 1999) is in line with the observed regular increase of the free tropospheric $\mathrm{HCOOH}$ loading during March to June (see Fig. 3). The fast September-October decrease is clearly associated with the progressive slowing of these processes. Overall, the observed seasonal modulation of the $\mathrm{HCOOH}$ loading is also in phase with the annual solar insolation cycle measured at the Jungfraujoch by the Swiss Federal Office of Meteorology and Climatology (http://www.meteosuisse.admin.ch) and with the moisture content in the atmosphere above the Alpine Plateau, which we monitor as part of our involvement in the NDACC (Network for the Detection of Atmospheric Composition Change (see http://www.ndacc.org). However, it is off-phase with our observed seasonal modulation of $\mathrm{CO}_{2}$ above the site (Zander et al., 2008) whose minimum is an indicator of high vegetation photosynthesis activity during springtime (a feature also evoked by Talbot et al. (1997b; see Appendix A). While special attention has been given to correct for the spectral interference by the HDO line at $1104.8759 \mathrm{~cm}^{-1}$ (see Sect. 4 and Fig. 1), the moisture content above the Jungfraujoch (showing a minimum from January to March and a maximum in July-August) is likely to affect the variability of formic acid which is highly soluble, but no clear correlation has been established statistically between them. It is also worth noting that the annual variation of the mean $\mathrm{HCOOH}$ loading above the Jungfraujoch is in excellent phase with the local aerosol concentration reported by Baltensperger et al. (1997) for the period 1988 to 1996.

In Table 4 we compare findings obtained here with results from other field investigations identified in the post-1990 literature, with emphasis on free tropospheric $\mathrm{HCOOH}$ measurements at Northern mid-latitudes. Details on these comparisons and related comments are provided in Appendix A.

The large variability in the tropospheric $\mathrm{HCOOH}$ loading is ubiquitously confirmed by the standard deviations associated with most Northern mid-latitude field measurements retained in Table 4, independently of their observational ap- proach, their temporal extent and geographic location, and the specificity of the surrounding milieu (e.g., marine versus continental; boundary layer versus free troposphere). Considering the magnitudes of these standard deviations, it is encouraging to notice that there is commensuration, within a factor 2 , among most mean values reported in Table 4, including relevant time-coincident Jungfraujoch findings provided in bold (between parentheses) in column 3 .

Few, isolated comparisons between $\mathrm{HCOOH}$ observations and model calculations have shown that the latter generally predict $\mathrm{HCOOH}$ concentrations significantly lower than measured. For example, Baboukas et al. (2000) report a factor 9 difference between boundary layer observations during a $63^{\circ} \mathrm{N}-39^{\circ} \mathrm{S}$ Atlantic ship cruise and the 3-D global tropospheric chemistry-transport MOGUNTIA model (e.g. Kanakidou and Crutzen, 1999; Poisson et al., 2000). Similarly, mean free tropospheric concentrations of $\mathrm{HCOOH}$ derived from infrared solar spectra recorded at Kitt Peak Observatory $(2.09 \mathrm{~km}$ a.s.1., southern Arizona, USA) and analyzed by Rinsland et al. (2004) were an order of magnitude higher than related calculations with the MATCH-MPIC 3D model (Von Kuhlmann et al., 2003); this latter difference remains large even after halving it as a consequence of the new $\mathrm{HCOOH}$ spectroscopic parameters produced by Perrin and Vander Auwera (2007). According to Von Kuhlmann et al. (2003), the most likely reason for the large differences between $\mathrm{HCOOH}$ field observations and model calculations is that the latter only consider $\mathrm{HCOOH}$ production from the first order ozonolysis of alkenes (mainly isoprene) totaling $17 \mathrm{Tg} / \mathrm{yr}$, and an additional $14 \mathrm{Tg} / \mathrm{yr}$ from biomass burning. Even more recent model runs incorporating some direct emissions of carboxylic acids resulting from biomass burning (i.e., Ito et al., 2007) have not yet approached reasonable commensuration with field investigations through the troposphere. The modelers are aware of other potential $\mathrm{HCOOH}$ sources, e.g., direct emissions from forests and land vegetation, and contributions from anthropogenic releases by 
domestic heating and road traffic, but their optimal model implementation demands more reliable evaluations of seasonrelated emission rates versus environmental specifics of regional areas.

\section{$7 \quad$ Summary and conclusions}

The spectrometric analysis of 8256 solar spectra recorded regularly at the Jungfraujoch during over 1500 clear-sky days between September 1985 to September 2007 with very high spectral resolution Fourier transform infrared spectrometers has allowed various aspects of the free tropospheric loading of formic acid $(\mathrm{HCOOH})$ to be characterized above the mountainous Swiss Alpine plateau. The investigation used the new, more accurate set of spectroscopic parameters for the $\mathrm{HCOOH} v_{6}$ band Q branch at $1105 \mathrm{~cm}^{-1}$ produced by Perrin and Vander Auwera (2007), which resulted in retrieved formic acid total column abundances nearly a factor 2 smaller $(1.97 \pm 0.08$ from a representative test performed here) and definitely more accurate than if retrieved with the older parameters (see Sect. 3). Adoption of a two-step retrieval approach involving fittings of five micro-windows helped to optimally account for all major temperature-sensitive interferences such as $\mathrm{HDO}$ and $\mathrm{O}_{3}$, as well as continuum-type, long-term evolving absorptions by $\mathrm{CCl}_{2} \mathrm{~F}_{2}$ and $\mathrm{CHClF}_{2}$ (see Sect. 4). The main sources of uncertainty, both random and systematic, have been discussed at the end of Sect. 4, and quantified in Table 1, with the total random and systematic root square sums (RSS), respectively evaluated at 13 and $18 \%$ maximum.

Overall, the individual $\mathrm{HCOOH}$ column abundances of the 22-year long database (Fig. 2a) compacted into daily- and monthly means (respectively Figs. $2 b$ and 3 ) have unambiguously confirmed the occurrence of significant sub-day, diurnal-, and day-to-day variability all along the reported period. Causes for such short-term variability have been evoked in the introductory Sect. 1.

For the first time, the seasonal modulation of the free tropospheric mean daytime $\mathrm{HCOOH}$ loading above a Northern mid-latitude site has been assessed statistically at the 1- $\sigma$ confidence level (Fig. 3), showing a broad maximum during June-July-August and a November-December-January minimum, with a mean maximum to minimum ratio of 4 . At the same confidence level, the shaded area in Fig. 3 reflects primarily the observed inter-annual variability noticeable in Fig. 2. A month-specific climatology of the mean daytime HCOOH loading above the Jungfraujoch for the period 1985 to 2007 is quantified in Table 2. The seasonal modulation, characterized by a regular tropospheric $\mathrm{HCOOH}$ increase from March to June and a relatively fast decrease during September and October, is in phase with various groundlevel biogenic vegetation metabolisms described, e.g., by Kesselmeier and Staudt (1999), which are largely dependent on solar insolation, local temperature and related atmo- spheric dynamics, as well as specific regional soil coverage. The influence of the vegetation photosynthesis is corroborated here by the observed off-phase loading of $\mathrm{CO}_{2}$ above the Jungfraujoch versus the seasonal $\mathrm{HCOOH}$ modulation. Thermal convection resulting from solar irradiation appears to dominate local releases of source gases at the seasonchanging ground cover, followed by their transport up to and above the Jungfraujoch site, where they mix and dilute with trade winds.

The lack of a long-term November-December-January change (see Fig. 2 and Sect. 6) observed here supports the idea that the background formic acid content in the remote troposphere above the Alpine plateau is essentially of natural (direct or indirect) recurring biogenic origin, in line with findings by Legrand et al. (2003). This view is further supported by the research reported by Glasius et al. (2001), who found that the ${ }^{14} \mathrm{C}$ content measured in boundary layer carboxylic acids at various remote sites through Western Europe is indicative of a natural biogenic contribution in excess of $80 \%$ to the atmospheric $\mathrm{HCOOH}$ loading.

While the first evidence for the presence of $\mathrm{HCOOH}$ in the upper troposphere was based on remote solar FTIR observations from aboard a stratospheric balloon platform (Goldman et al., 1984), subsequent studies have largely relied on local in situ ground-, sea- and airborne measurements. However, numerous recent Northern mid-latitude $\mathrm{HCOOH}-$ related investigations listed in Table 4 (and briefly described in Appendix A) show that the infrared remote sensing approach with fast FTIR spectrometers has again been successfully implemented in applications based on either the solar occultation- or the thermal limb emission mode. In particular, the global distributions of upper tropospheric formic acid by the ACE-FTS (González Abad et al., 2009) and the MIPAS-ENVISAT (Grutter et al., 2010) space instruments are definitely "first" achievements likely to help understanding and modeling the $\mathrm{HCOOH}$ distribution on a global scale. In line with the comprehensive laboratory intercomparison exercise of biomass-burning emissions (Christian et al., 2004) evoked in Sect. 3, we believe that a concerted effort should be undertaken to identify measurement techniques and observational platforms, allowing to achieve optimal complementarity, temporal continuity and spatial coverage, with focus on accuracy, detection sensitivity, and longterm stability. Observation priorities of sets of key species and documentation of ancillary environmental parameters should be further identified in concert with modeling groups.

The potential of modern ground-based, fast, wide bandpass FTIR spectrometers using the sun as source of radiation, is their ability to regularly record solar spectra over the entire middle-infrared spectral domain (from 2 to $15 \mu \mathrm{m}$ ) under daytime clear sky conditions, with very high spectral resolution and large signal-to-noise ratios. This remote sensing technique, which was pioneered at Kitt Peak during the 1970s by Brault (1978), progressively supplanted slow and bulky grating spectrometers used till then for solar 
Table 4. Comparison of recent free tropospheric $\mathrm{HCOOH}$ concentrations at Northern mid-latitudes with relevant time-coincident mean values above the Jungfraujoch (all in pptv).

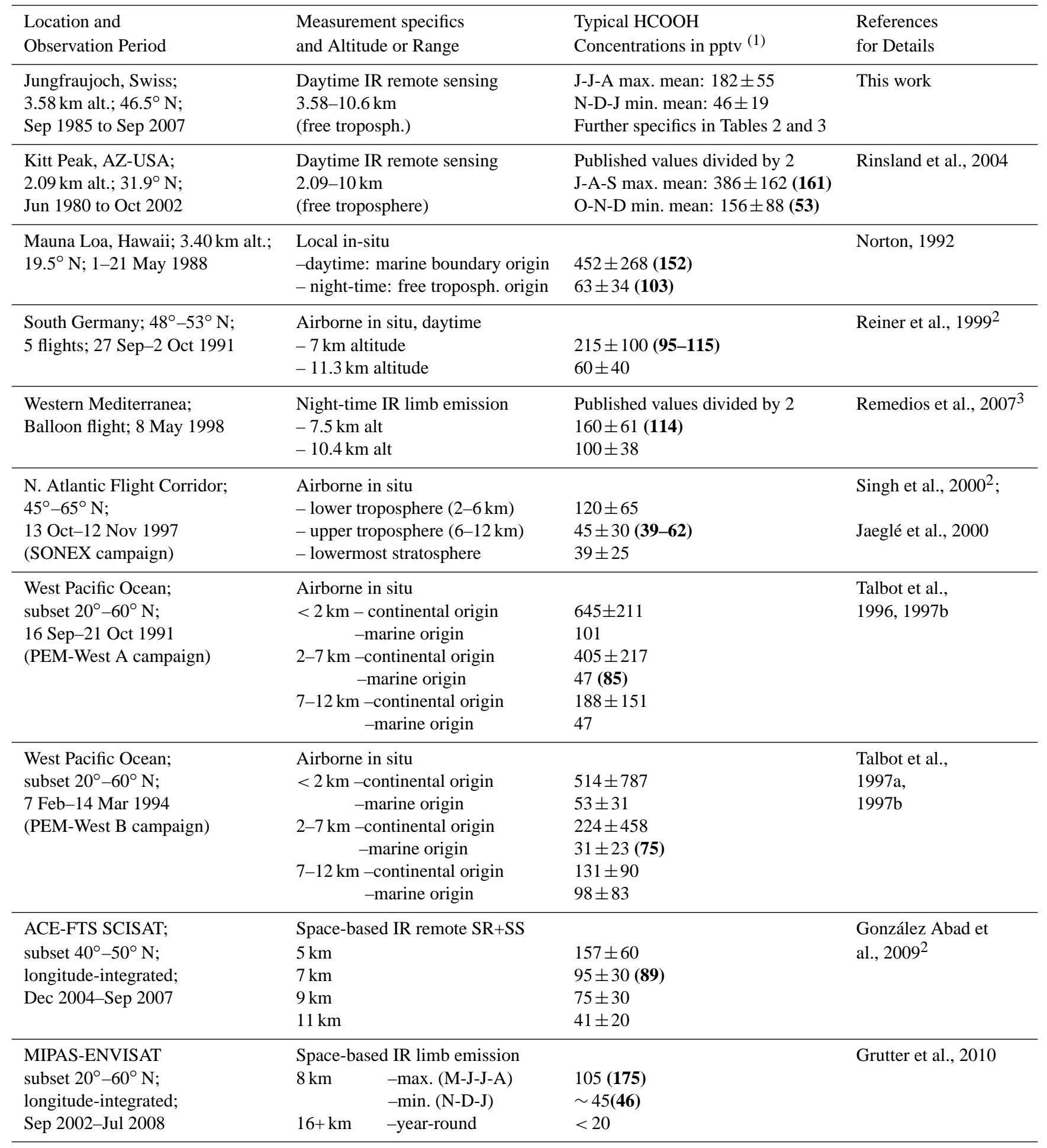

1 values in bold between parentheses refer to relevant time-coincident Jungfraujoch findings discussed in Appendix A. All reported uncertainties are 1-sigma standard deviations, except: ${ }^{2}$ uncertainties estimated from Figures in related references; ${ }^{3}$ uncertainties are total systematic errors. 
observations made at the Jungfraujoch since the early 1950 (Migeotte et al., 1956; Delbouille and Roland, 1995). At the onset of the 1980s, the Jungfraujoch solar observation strategy became increasingly dictated by the need to support the Montreal- and the emerging Kyoto Protocols, thus focusing on the monitoring of stratospheric ozone and ozonedepleting inorganic gases of the $\mathrm{NO}_{\mathrm{y}}$ and $\mathrm{Cl}_{\mathrm{y}}$ families, as well as all related ground-released organic natural- and anthropogenic greenhouse gases with significant absorption strengths in the thermal infrared (e.g., Mahieu et al., 2000, 2007; Zander et at., 2005). In addition to these Protocolrelated target gases, the middle-infrared domain further contains characteristic absorption signatures of many other organic trace constituents (Zander et al., 2008) among which we chose to deal here with $\mathrm{HCOOH}$, because of its indirect influence on the oxidizing capacity of the troposphere, as well as its critical, ubiquitous contribution to the boundary layer acidity.

An effort dealing with correlations between $\mathrm{HCOOH}$ and other species (i.e., $\mathrm{CO}, \mathrm{HCN}, \mathrm{C}_{2} \mathrm{H}_{2}, \mathrm{C}_{2} \mathrm{H}_{6}, \mathrm{H}_{2} \mathrm{CO}$, $\mathrm{CH}_{3} \mathrm{OH}$ ) also monitored at the Jungfraujoch, is currently in progress. Specifics regarding these databases and preliminary correlations can be obtained by contacting Emmanuel.Mahieu@ulg.ac.be.

Considering the original $\mathrm{HCOOH}$-related findings reported in this work, and found to be commensurate to within a factor 2 with numerous other Northern mid-latitude field observations, it would be interesting to see a modeling effort focusing on this zonal part of the Earth. A particular attention should even focus on the Western European Continent, incorporating adjusted emission sources reported by Legrand et al. (2003) for summer 2000 over France. Topdown versus bottom-up modeling outcomes may also shed light on the possible occurrence of indirect production of formic acid within the free troposphere.

\section{Appendix A}

\section{Comparisons with other free tropospheric $\mathrm{HCOOH}$ field measurements at Northern mid-latitudes}

In the following paragraphs, we briefly discuss findings derived here versus results from other field campaigns reported in the literature, with emphasis on free tropospheric $\mathrm{HCOOH}$ evaluations at Northern mid-latitudes. Relevant Jungfraujoch findings are provided (in bold) in column 3 of Table 4; they are listed for comparison at the altitude (or altitude range) nearest to $6.2 \mathrm{~km}$, which is the central mass altitude for the $\mathrm{HCOOH}$ loading above the Jungfraujoch. Where relevant, boundary layer $\mathrm{HCOOH}$ concentrations are also evoked.

Because of observational- and analytical similarity, we first focus on the long-term $\mathrm{HCOOH}$ investigation reported by Rinsland et al. (2004). This research was based on the analysis of solar spectra recorded between June 1980 and
September 2002 at the Kitt Peak National Solar Observatory $\left(31.9^{\circ} \mathrm{N}, 111.6^{\circ} \mathrm{E}, 2.09 \mathrm{~km}\right.$ altitude), a mountain top site located in the semiarid Sonora desert in South-West Arizona, USA. It resulted in a retained set of 116 daily mean constant VMRs of $\mathrm{HCOOH}$ through the free troposphere out to $10 \mathrm{~km}$ altitude, much sparser than the 1501 days available here over a similar time period (22 years). Due to large variability in these daily means, Rinsland et al. (2004) reported quarterly (3 months) mean VMR values, namely (356 \pm 179$)$ pptv for J-F-M, $(\sim 680 \pm 300)$ pptv for A-M-J, a maximum of (792 \pm 323$)$ pptv during J-A-S, and a minimum of $(313 \pm 175)$ pptv in O-N-D, with the uncertainties corresponding to statistical means of the intervening daily averages. The magnitude of the quarterly uncertainties prevented a seasonal cycle to be assessed statistically, thus the cautious terming "evidence for a seasonal cycle" in the title of their paper (Rinsland et al., 2004; see their Fig. 4). Compared with our present findings and other Northern midlatitude ones (i.e., Norton et al., 1992; Talbot et al., 1997a, b; Reiner et al., 1999; Singh et al., 2000; Remedios et al., 2007; Gonzáles Abad et al., 2009; Grutter et al., 2010), the mean Kitt Peak values appear exceedingly high, more representative of remote boundary layer concentrations documented in various reviews (e.g., Kesselmeier and Staudt, 1999; Khare et al., 1999; Poisson et al., 2000). However, lowering them by 2 in accordance with the new improved spectroscopic parameters of Perrin and Vander Auwera (2007), brings them closer to expectation as shown in Table 4. Despite this absolute halving, they still remain high compared to the mean Jungfraujoch values. This discrepancy may result from the fact that Kitt Peak is $15^{\circ}$ further south and a full $1.5 \mathrm{~km}$ lower in altitude than the Jungfraujoch, thus experiencing enhanced convective transport of warmer boundary layer air masses which carry formic acid and various precursor gases up to and above the site.

Another noticeable difference deals with the relative 3month maximum (J-A-S) over minimum (O-N-D) concentration ratio found equal to 2.5 at Kitt Peak, which is lower than the maximum (J-J-A) to minimum (N-D-J) ratio of 4.0 found for the Jungfraujoch. If we strictly consider the quarterly periods adopted for Kitt Peak, then the Jungfraujoch J-A-S over the O-N-D mean VMRs derived from Table 2 return a ratio of 3.0, which is in reasonable agreement when accounting for the respective systematic uncertainties, namely $28 \%$ for Kitt Peak and $18 \%$ for the Jungfraujoch. Rinsland et al. (2004) pointed to the sparseness of the Kitt Peak database, which prevented quantifying diurnal- or inter-annual variations, nor a long-term trend. Whether the reported occurrence of both the maximum and the minimum $\mathrm{HCOOH}$ loading above Kitt Peak during the two adjacent last quarters of the year is real or the result of insufficient internal consistency of the database remains an open question.

Earlier HCOOH investigations (e.g., Talbot et al. (1989), from in situ air samplings in Virginia, USA; Arlander et al. (1990) from in situ air samplings along a sea cruise in 
the Pacific and Indian Oceans; Moody et al. (1991), by the chemical analysis of precipitations at Amsterdam Island; Baboukas et al. (2000) from in situ air samplings during a $\mathrm{N}-\mathrm{S}$ Atlantic sea cruise) suggested some evidence for a seasonal variation, with maxima during local summer and minima in winter, but their significance was statistically weak, because of time limited campaigns.

It is worth evoking here the analysis of an ice core extracted at the remote Col du Dôme ( $4250 \mathrm{~m}$, French Alps) by Legrand et al. (2003), who report records of carboxylic acids covering the period from 1925 to 1995 . Formate-related findings showed a seasonal cycle, with somewhat "chaotic" mean summer/winter contrasts, i.e., 3 from 1930 to 1940, 1.7 between 1950 and 1975, 7 from 1980 to 1990, and a ratio dropping towards 4 during the last years of their time base. This latter ratio is commensurate with the mean seasonal peak-to-peak modulation of $\mathrm{HCOOH}$ derived from our Fig. 3 for the past two decades, i.e., 4. The authors attributed the changes in the maxium to minimum seasonal contrast to the evolving magnitude of summer versus winter thermal convection of air masses from the boundary layer to the free troposphere. The Col du Dôme record also showed that 1985 to 1995 summertime concentrations of formate were close to values determined between 1925 and 1950, which led Legrand et al. (2003) to conclude that the more recent impact of industry-related anthropogenic contributions to atmospheric $\mathrm{HCOOH}$ remains weak. This conclusion is corroborated by Glasius et al. (2001) who found that the ${ }^{14} \mathrm{C}$ content measured in boundary layer carboxylic acids at remote sites through Western Europe is indicative of a natural biogenic contribution well in excess of $80 \%$ to the total $\mathrm{HCOOH}$ loading.

Incidentally, Legrand et al. (2004) also reported on another multiple gas in situ study, namely at the Antarctic station Dumont d'Urville (DdU; $60^{\circ} \mathrm{S}, 140^{\circ} \mathrm{E}, 140 \mathrm{~m}$ a.s.l.) between 1997 to 2002, with mean $\mathrm{HCOOH}$ mixing ratios of about $70 \mathrm{pptv}$ during local winter (May to August; polar night), increasing to $\sim 200 \mathrm{pptv}$ during local summer (November to February). Little influence of air masses origin suggested this seasonal variation to be characteristic of the Antarctic Ocean biogenic emissions. Considering the "extreme" marine environment, nearly free of vegetation and industrial activity, it is relevant to notice that the local $\mathrm{HCOOH}$ concentrations reported by Legrand et al. (2004) indicate (1) a mean DdU summer/winter ratio of 3, which is in line with the mean values reported for both Northern midlatitude Jungfraujoch and Kitt Peak continental sites during the past 2 decades, and (2) daytime concentrations some 30 pptv higher than night-time ( $\sim 50 \mathrm{pptv})$ values during a summer test, thus in line with mean N-D-J sunrise to daytime concentrations found above the Jungfraujoch as documented in Tables 2 and 3.

How do the $\mathrm{HCOOH}$ findings derived in situ by Norton (1992) during a short 1-21 May 1988 campaign at the Mauna Loa Observatory $\left(\mathrm{MLO} ; 19.5^{\circ} \mathrm{N}, 155.6^{\circ} \mathrm{W}\right)$ compare with those reported here? MLO is located on the Hawaii Island, in the middle of the Pacific Ocean, at an altitude of $3400 \mathrm{~m}$ (similar to that of the Jungfraujoch) on the northern slope of the still active Mauna Loa volcano. Average local $\mathrm{HCOOH}$ day- and night-time concentrations and standard deviations were reported equal to $452 \pm 268 \mathrm{pptv}$ and $63 \pm 34$ pptv, respectively. Owing to the MLO altitude and geographic location, Norton et al. (1992) concluded that the daytime values are characteristic of local, sub-tropical marine air masses modified by contact with the island ground and vegetation along their way to the site, whereas the nighttime ones are representative of descending air from the free troposphere. While the latter are in line with those reported by Talbot et al. (1997a, 1997b) for marine air masses above $2 \mathrm{~km}$ during two Pacific Exploratory Missions, namely the PEM-West A and B campaigns as well as with other free tropospheric measurements referred to in Table 4, the MLO findings in advected marine air during daytime are substantially higher than those found below $2 \mathrm{~km}$ during both PEMWest campaigns. The daytime MLO values are also much higher than observed by Arlander et al. (1990), i.e. an average $\mathrm{HCOOH}$ concentration of about $150 \mathrm{pptv}$ during the last $3000 \mathrm{~km}$ of their $7^{\circ} \mathrm{N}$ longitudinal leg cruise between Singapore and Hawaii. The local MLO day- to night-time ratio of 7 contrasts significantly with the mean Jungfraujoch culmination/sunrise ratio of 1.5 for the month of May, specifically derived from the red lines in Fig. 4 and reported in Table 3. This large diurnal ratio difference may result from the fact that MLO is a sub-tropical island site experiencing stronger daytime thermal convection, with marine background air masses advecting then convecting efficiently (a kind of "chimney effect") towards the site over warm ground and dense local growing vegetation. Also relevant to this high MLO day/night ratio of $\mathrm{HCOOH}$ are findings reported by Arlander et al. (1990) during an April-July 1987 cruise transect between $50^{\circ} \mathrm{N}$ to $40^{\circ} \mathrm{S}$ in the Pacific and Indian Oceans, near $195^{\circ} \mathrm{W}$ longitude. They observed broad maxima for both formic and acetic acids centred at $15-20^{\circ} \mathrm{N}$, and suggested they may result from increased biogenic emissions of olefinic precursors emitted by marine microbiota, then volatilized to the atmosphere and subsequently photo-oxidized to form organic acids (Keene and Galloway, 1988). A similar maximum was observed around $20^{\circ} \mathrm{N}$ by Baboukas et al. (2000) during a $30^{\circ} \mathrm{W}$ Atlantic transect from $63^{\circ} \mathrm{N}$ to $39^{\circ} \mathrm{S}$ between 11 October to 2 November 1996. Such marine features may have influenced $\mathrm{HCOOH}$ daytime concentrations at MLO. When only considering those mean daytime $\mathrm{HCOOH}$ concentrations strictly associated with the night-time data retained by Norton (1992; his Fig. 3), the day-to night ratio reduces from 7 to 5 , which still remains relatively high. Although based on limited datasets, $\mathrm{HCOOH}$ diurnal ratios reported in the consulted literature, namely about 2 by Arlander et al. (1990), 2.5 by Khwaja (1995), 2.5 by Kajii et al. (1997), 2.2 by Baboukas et al. (2000), and 1.7 by Legrand et al. (2004), are in closer agreement with the mean 
Jungfraujoch ratio of 1.5, than with the Mauna Loa one of 7 .

Further documented in Table 4 are airborne investigations of $\mathrm{HCOOH}$ in the free troposphere, based on in situ measurements at different northern mid-latitude locations. In particular, between 27 September and 2 October 1991, Reiner et al. (1999) performed five flights over southern Germany, only a few degrees North of the Jungfraujoch. They measured $\mathrm{HCOOH}$ concentrations in the upper troposphere, showing a regular decrease from mean $215 \pm 100 \mathrm{pptv}$ at $7 \mathrm{~km}$ to $60 \pm 40 \mathrm{pptv}$ at $11.3 \mathrm{~km}$ altitude (this slope was taken into account in the confection of the $\mathrm{HCOOH}$ a priori profile adopted in the present retrieval process; see Sect. 2). The mean tropospheric VMR concentration above the Jungfraujoch read off the thick curve of Fig. 3 for late September is equal to $95 \pm 38$ pptv, while a more specific value of $115 \pm 18$ pptv was derived from 17 spectra recorded on 3 and 4 October 1991. If we reasonably assume that the Reiner et al. (1999; their Fig. 2c) slope of $\mathrm{HCOOH}$ applies further down through the troposphere, then their corresponding mean VMR concentration would be larger than the mean Jungfraujoch one by almost a factor 2, but still commensurate within the standard deviations of both data sets.

Limited but original measurements of $\mathrm{HCOOH}$ concentrations in the upper troposphere over the Western Mediterranean region have been reported recently by Remedios et al. (2007). They were based on the spectrometric analysis of the $\mathrm{HCOOH} v_{6}$ band observed in thermal limb emission spectra recorded during night-time on 8 May 1998 with the cryogenically cooled MIPAS-B2 FTIR balloon spectrometer (Friedl-Vallon et al., 2004). Altitude-specific concentrations reported by Remedios et al. (2007) using the old $v_{6}$ band intensities of $\mathrm{HCOOH}$ were equal to $320 \pm 120 \mathrm{pptv}$ and $200 \pm 80 \mathrm{pptv}$, respectively at 7.5 and $10.4 \mathrm{~km}$ altitude. As can be seen in Table 4, dividing these values by 2 to account for the new spectroscopy (Perrin and Vander Auwera, 2007) brings them in reasonable agreement with the values found by Reiner et al. (1999), and commensurate with our mean tropospheric concentration of $114 \pm 19$ pptv derived from Jungfraujoch observations made in the very early morning of 8 May 1998. Historically speaking, Goldman et al. (1984) reported the first tentative identification of $\mathrm{HCOOH}$ in the free troposphere, i.e, $600 \mathrm{pptv}$ at $8 \mathrm{~km}$ and $400 \mathrm{pptv}$ at $10 \mathrm{~km}$, based on the analysis of solar occultation spectra recorded from aboard a stratospheric balloon instrument above Arizona (USA). Even halving their reported values to account for the new spectroscopy (Perrin and Vander Auwera, 2007) still leaves them quite high in comparison with the Reiner et al. (1999) and the Remedios et al. (2007) values; one of the causes certainly lies in the quite poor knowledge, at that time, of many interfering gases and their related spectroscopy (in particular $\mathrm{HDO}$ and $\mathrm{O}_{3}$, whose improvement has been spectacular since the early 1990s).

The goal of the SONEX (Subsonic Assessment Ozone and Nitrogen Oxide Experiment) airborne field campaign of October 13 to November 12, 1997 (Singh et al., 2000; Jaeglé et al., 2000) was to evaluate the impact of aircraft emissions on the $\mathrm{HO}_{\mathrm{x}}-\mathrm{NO}_{\mathrm{x}}-\mathrm{O}_{3}$ chemistry in the troposphere, between 2 and $12 \mathrm{~km}$ altitude, with focus on the North Atlantic flight corridor area between $40^{\circ}$ to $65^{\circ} \mathrm{N}$ latitude. Among many oxygenated organic species concurrently studied in situ, mean $\mathrm{HCOOH}$ concentrations were found equal to about $120 \pm 65 \mathrm{pptv}, 45 \pm 30 \mathrm{pptv}$, and $39 \pm 25 \mathrm{pptv}$, respectively in the lower $(2-6 \mathrm{~km})$ and upper $(6-12 \mathrm{~km})$ troposphere, and in the lowermost stratosphere (see Table 4). Overall, these values agree well with the mean tropospheric VMR above the Jungfraujoch read off the thick curve of Fig. 3 for late October, namely $62 \pm 22$ pptv. This comparison is a sound one, as Fuelberg et al. (2000) found that the SONEX campaign occurred during a year-to-year climatologically average situation. However, a look at Fig. 2 shows that 1997 was a year with an overall relatively low HCOOH loading above the Jungfraujoch. This is substantiated by observations specifically made at the Jungfraujoch during the SONEX period (i.e., 30 measurements encompassing 12 days between 19 October and 11 November 1997) and returning a mean VMR of $39 \pm 17$ pptv. While this lower value remains commensurate with the SONEX findings when considering the respective uncertainties, one can't exclude that some SONEX soundings may have been made in air masses affected by biogenic emissions originating from the Eastern rim of the North American sub-continent. Based on all SONEX measurements made in the upper troposphere ( 8 to $12 \mathrm{~km}$ ), Jaeglé et al. (2000) classified the sounded air masses into six categories according to their origin, namely local background, stratospheric influence, cirrus clouds, and convection of tropical marine-, mid-latitude marine-, and continental air masses. Among these categories, the extreme median concentrations of $\mathrm{HCOOH}$ ranged from $37 \mathrm{pptv}$ in local background air to $21 \mathrm{pptv}$ in convected continental air masses, with an occurrence-weighted average equal to $33.2 \mathrm{pptv}$. Noteworthy is the fact that the first three categories returned a median $\mathrm{HCOOH}$ concentration of $35 \pm 2$ pptv in about $80 \%$ of the measurements, while the categories dealing with convection air masses showed $\mathrm{HCOOH}$ medians of only $23 \pm 2$ pptv. Whether this difference is indicative of the presence of a $\mathrm{HCOOH}$ source in the upper troposphere is worth of further consideration.

During two airborne "Pacific Exploratory Missions" (PEM) over the western Pacific basin, east of the Asian rim, namely PEM-West A (from 16 September to 21 October 1991) and PEM-West B (from 7 February to 14 March 1994), HCOOH was one of the numerous compounds simultaneously investigated in situ between 0.3 and $12.5 \mathrm{~km}$ altitude. The timing of the campaigns was chosen to characterize the eastward Asian outflow of material to the North Pacific troposphere, which is lowest during fall and highest during springtime, when the high pressure oceanic system is optimally displaced from West to East (Prospero et al., 1985). Overall findings derived from the PEM missions have been reported by Talbot et al. (1996a, 1997a, b) 
according to air mass origin (i.e., continental south (0 to $20^{\circ} \mathrm{N}$ ), continental north $\left(20\right.$ to $\left.60^{\circ} \mathrm{N}\right)$ and marine (air masses that were over the Pacific for at least 5 days)), and over specific altitude layers (i.e., $<2 \mathrm{~km}, 2-7 \mathrm{~km}$, and $7-$ $12 \mathrm{~km}$ ). Relevant $\mathrm{HCOOH}$ data collected over the $20^{\circ}$ to $60^{\circ}$ latitude band are listed in Table 4. Contrary to the expected continental air-mass outflow evoked above, the $\mathrm{HCOOH}$ concentrations were lower during PEM-West B (late winter) compared to PEM-West A (early fall). Talbot et al. (1997b) related the observed seasonal difference of monocarboxylic acids to depressed biogenic vegetation metabolisms during PEM-West $\mathrm{B}$, as evidenced by a $2-3 \%$ increase in concurrently measured $\mathrm{CO}_{2}$ concentrations. While the PEM campaigns were occurring east of the Asian continent, the Jungfraujoch is located east of the Atlantic Ocean, both under the influence of dominant westerly winds. It is therefore likely that, on average, the $\mathrm{HCOOH}$ loading above the Jungfraujoch predominantly reflects characteristics of free tropospheric marine air masses that have progressively mixed with continental background (occasionally "polluted") air on their way towards the Alpine plateau. This was already suggested by Hartmann et al. (1989) who found that $\mathrm{HCOOH}$ mixing ratios measured during three airplane flights over Western Germany averaged $170 \pm 60$ pptv in westerly marine air flows, substantially lower than those found in intrusion flows from other directions. The mean $\mathrm{HCOOH}$ concentrations above the Jungfraujoch, read off the thick curve in Fig. 3 for the periods of PEM-West A and B, namely $85 \pm 38$ pptv and $75 \pm 20$ pptv, are in better agreement with mean concentrations found in characteristic marine air masses during these campaigns (see Table 4).

The first near global distribution of formic acid between $5 \mathrm{~km}$ altitude and the tropopause has been reported recently by González Abad et al. (2009). It is based on remote solar occultation observations made at sunrise and sunset between February 2004 and September 2007 with the ACE-FTS equipment operating aboard the Canadian SCISAT satellite (Bernath et al., 2005). The instrument scanning speed provides a vertical resolution of 2 to $3 \mathrm{~km}$ in targeted concentration profiles, but only during a few minutes at local sunrises and sunsets. The $\mathrm{HCOOH}$ retrieval analysis (Boone et al., 2005) is based on the fitting of the $v_{6}$ band Q-branch and the updated spectroscopic parameters (Perrin and Vander Auwera, 2007) as adopted here. The $\mathrm{HCOOH}$ profiles determined by ACE over the continental USA have been inter-compared with near time-coincident solar occultation observations made over New Mexico (USA) by the MKIV-FTIR balloon instrument (Toon, 1991), with profiles agreeing to within their respective one standard deviation. Overall also, both inter-compared datasets confirm the decrease of the $\mathrm{HCOOH}$ concentration with increasing altitude, thus in line with earlier airplane observations (e.g., Reiner et al., 1999; Singh et al., 2000; Talbot et al., 1996a, 1997b) and with the slope adopted for our $\mathrm{HCOOH}$ a priori profile (see Sect. 2). The pole-to-pole ACE data for the period December 2004 to September 2007 have been reported as average VMR profiles of $\mathrm{HCOOH}$ in $10^{\circ}$ wide latitudinal bins integrated over all longitudes (see Table 1 at http://www.atmos-chem-phys-discuss.net/9/12465/ 2009/acpd-9-12465-2009-supplement.pdf). Mean numerical values found in the $40^{\circ}$ to $50^{\circ}$ North latitude zone (which encompasses the Jungfraujoch location) show discrete concentrations of $157,95,75$ and $41 \mathrm{pptv}$, respectively at 5,7 , 9 and $11 \mathrm{~km}$ altitude, which are in good agreement with a yearly mean combined sunrise-sunset free tropospheric concentration of $83 \pm 32$ pptv derived from our Table 3 .

We conclude this Appendix with another satellite-based research recently published by Grutter et al. (2010), dealing with the global distribution and variability of formic acid in the upper troposphere. The $\mathrm{HCOOH}$ concentration profiles between 8 and $18 \mathrm{~km}$ altitude were derived from Earth's limb infrared emission spectra recorded between September 2002 and July 2008 with the MIPAS-ENVISAT (Michelson Interferometer for Passive Atmospheric Sounding-Environment Satellite) instrument (Fischer et al., 2008). As in the present work, Grutter et al. (2010) used the same HCOOH v $v_{6}$ Qbranch feature near $1105 \mathrm{~cm}^{-1}$ as well as the new set of spectroscopic line parameters from Perrin and Vander Auwera (2007). Of relevance here is a subset of findings derived by Grutter et al. (2010; see their Figs. 2, 4 and 6) at $8 \mathrm{~km}$ altitude and longitudinally integrated over the 20 $60^{\circ}$ North latitude zone, namely: (i) their reported seasonal pattern, with largest $\mathrm{HCOOH}$ concentrations (typically 100 110 pptv) between May and August, and minimum values (around 45 pptv) during November to January, which agrees very well in time with our mean seasonal modulation (see Fig. 3); (ii) their related maximum to minimum ratio of 2 , which contrasts with the ratio 4 found here (see Fig. 3 and Table 2); this difference very likely results from the predominance of $\mathrm{HCOOH}$ emissions at the ground and progressive dilution, deposition and increasing lifetime during the convective transport to higher altitude; (iii) the lack of a diurnal variation in the MIPAS observations over the 8 to $16 \mathrm{~km}$ altitude range at Northern mid-latitudes, while our Fig. 4 and Table 3 provide statistical evidence for an overall maximum $\mathrm{HCOOH}$ loading around mid-day as compared to sunrise and sunset; here also, the $\mathrm{HCOOH}$ lifetime change versus altitude (hours in the boundary layer and days in the upper troposphere) can account for the observed diurnal modulation attenuation/vanishing at higher altitudes. Finally, the slope of the mean MIPAS profiles at Northern mid-latitudes confirms the soundness of our adopted altitude-dependent $\mathrm{HCOOH}$ a priori profile characterized in Sect. 2.

Acknowledgements. This work is part of an overall atmospheric monitoring effort conducted at the University of Liège and primarily financed by the Belgian Federal Science Policy Office, the Belgian Fonds National de la Recherche Scientifique, the Belgian Communauté Française, and the European Commission, all in Brussels. We thank all colleagues and collaborators who have contributed to the decades long production of the database used 
here, and to the operation and upgrading of the Liège laboratory at the Jungfraujoch. Thanks are also extended to colleagues from the Royal Observatory of Belgium and from the Belgian Institute for Space Aeronomy for their participation to intensive observational campaigns. Acknowledgements further go to the Swiss Jungfraubahnen for their continuous maintenance of and year-round access to the Jungfraujoch Station, as well as to the HFSJG Directorate for the logistic management of the numerous researches conducted at the Jungfraujoch site. The affiliation of the Jungfraujoch site to the International Network for the Detection of Atmospheric Composition Change (NDSCC) since 1989 has significantly boosted the implication of the University of Liège group in monitoring Earth's atmospheric composition changes, while further providing overall international visibility of various research activities performed at that site. J. VDA acknowledges financial support from the Belgian Fonds de la Recherche Scientifique (contracts FRFC and IISN), and the Actions de Recherches Concertées of the Communauté Française de Belgique. A. P. gratefully acknowledges financial support from INSU-CNRS (Institut National des Sciences de l'Univers). Analysis at the NASA Langley Research Center was supported by NASA's Upper Atmospheric Chemistry and Modeling Program (ACMAP) and Upper Atmospheric Research Program (UARP). We finally thank two designated referees whose remarks and suggestions have allowed clarifying various aspects raised in this research.

Edited by: A. Hofzumahaus

\section{References}

Andreae, M. O., Talbot, R. W., Andreae, T. W., and Harriss, R. C.: Formic and acetic acids over the central Amazon region, Brazil, 1: Dry season, J. Geophys. Res., 93, 1616-1624, 1988.

Arlander, D. W., Cronn, D. R., Farmer, J. C., Menzia, F. A., and Westberg, H. H.: Gaseous oxygenated hydrocarbons in the remote marine troposphere, J. Geophys. Res., 96, 16391-16403, 1990.

Baboukas, E. D., Kanakidou, M., and Mihalopoulos, N.: Carboxylic acids in gas and particulate phase above the Atlantic Ocean, J. Geophys. Res., 105, 14459-14471, 2000.

Baltensperger, U., Gäggeler, H. W., Jost, D. T., Lugauer, M., Schwikowski, M., E. Weingartner, and Seibert, P.: Aerosol climatology at the high-altitude site Jungfraujoch, Switzerland, J. Geophys. Res., 102, 19707-19715, 1997.

Bernath, P. F., McElroy, C. T., Abrams, M. C., Boone, C. D., Buttler, M., Camy-Peyret, C., Carleer, M., Clerbaux, C., Coheur, P.-F., Colin, R., DeCola, P., De Mazière, M., Drummond, J. R., Dufour, D., Evans, W. F. J., Fast, H., Fussen, D., Gilbert, K., Jennings, D. E., Llewellyn, E. J., Lowe, R. P., Mahieu, E., McConnell, J. C., McHugh, M., McLeod, S. D., Michaud, R., Midwinter, C., Nassar, R., Nichitiu, F., Nowlan, C., Rinsland, C. P., Rochon, Y. J., Rowlands, N., Semeniuk, K., Simon, P., Skelton, R., Sloan, J. J., Soucy, M.-A., Strong, K., Tremblay, P., Turnbull, D., Walker, K. A., Walkty, I., Wardle, D. A., Wehrle, V., Zander, R., and Zou, J.: Atmospheric Chemistry Experiment (ACE): mission overview, Geophys. Res. Lett., 32, L15S01, doi:10.1029/2005GL022386, 2005.

Boone, C. D., Nassar, R., Walker, K. A., Rochon, Y., McLeod, S. D., Rinsland, C. P., and Bernath, P. F.: Retrievals for the Atmo- spheric Chemistry Experiment Fourier transform spectrometer, Appl. Opt., 44, 7218-7231, 2005.

Brault, J. W.: Solar Fourier transform spectroscopy, in Proceedings of the JOSO Workshop on Future Solar Optical Observations, Needs and Constraints, Firenze, Italy; edited by: Godoli, G., Noci, G., and Reghin, A., 32-52, Baccini and Chiappi, Florence, Italy, 1978.

Chebbi, A. and Carlier, P.: Carboxylic acids in the troposphere, occurrence, sources and sinks: a review, Atmos. Environ., 24, 4233-4249, 1996.

Christian, T. J., Kleis, B., Yokelson, R. J., Holzinger, R., Crutzen, P. J., Hao, W. M., Shirai, T., and Blake, D. R.: Comprehensive laboratory measurements of biomass-burning emissions - Part 2: First intercomparison of open path FTIR, PTRMS, and GC-MS/FID/ECD, J. Geophys. Res., 109, D02311, doi:10.1029/2003JD003874, 2004.

Connor, B. J., Parrish, A., Tsou, J.-J., and McCormick, P.: Error analysis of the ground-based microwave ozone measurements during STOIC, J. Geophys. Res., 100, 9283-9291, 1995.

Delbouille, L. and Roland, G.: High Resolution Solar and Atmospheric Spectroscopy from the Jungfraujoch high-altitude Station, Opt. Eng., 34(9), 2736-2739, 1995.

Farmer, C. B. and Norton R. H.: A High-Resolution Atlas of the Infrared Spectrum of the Sun and the Earth Atmosphere from Space, Vol. I The Sun, NASA Reference Publication, 1224, 1989.

Fischer, H., Birk, M., Blom, C., Carli, B., Carlotti, M., von Clarmann, T., Delbouille, L., Dudhia, A., Ehhalt, D., Endemann, M., Flaud, J. M., Gessner, R., Kleinert, A., Koopman, R., Langen, J., López-Puertas, M., Mosner, P., Nett, H., Oelhaf, H., Perron, G., Remedios, J., Ridolfi, M., Stiller, G., and Zander, R.: MIPAS: an instrument for atmospheric and climate research, Atmos. Chem. Phys., 8, 2151-2188, doi:10.5194/acp-8-2151-2008, 2008.

Forrer, J., Rüttimann, R., Schneiter, D., Fischer, A., Buchmann, B., and Hofer, P.: Variability of trace gases at the high-Alpine site Jungfraujoch caused by meteorological transport processes, J. Geophys. Res., 105, 12241-12251, 2000.

Friedl-Vallon, F., Maucher, G., Kleinert, A., Lengel, A., Keim, C., Oelhaf, H., Fischer, H., Seefeldner, M., and Trieschmann, O.: Design and characterization of the balloon-borne Michelson Interferometer for Passive Atmospheric Sounding (MIPAS-2B), Appl. Opt., 3335-3355, 2004.

Fuelberg, H. E., Hannan, J. R., van Velthoven, P. F. J., Browell, E. V., Bieberbach, Jr., G., Knabb, R. D., Gregory, G. L., Pickering, K. E., and Selkirk, H. B.: A meteorological overview of the Subsonic Assessment Ozone and Nitrogen Oxide Experiment (SONEX) period, J. Geophys. Res., 105, 3633-3651, 2000.

Gardiner, T., Forbes, A., de Mazière, M., Vigouroux, C., Mahieu, E., Demoulin, P., Velazco, V., Notholt, J., Blumenstock, T., Hase, F., Kramer, I., Sussmann, R., Stremme, W., Mellqvist, J., Strandberg, A., Ellingsen, K., and Gauss, M.: Trend analysis of greenhouse gases over Europe measured by a network of ground-based remote FTIR instruments, Atmos. Chem. Phys., 8, 6719-6727, doi:10.5194/acp-8-6719-2008, 2008.

Glasius, M., Boel, C., Bruun, N., Easa, L. M., Hornung, P., Klausen, H. S., Klitgaard, K. C., Lindeskov, C., Møller, C. K., Nissen, H., Petersen, A. P. F., Kleefeld, S., Boaretto, E., Hansen, T. S., Heinmeier, J., and Lohse, C.: Relative contribution of biogenic and anthropogenic sources to formic and acetic acids in the atmospheric boundary layer, J. Gepohys. Res., 106, 7415-7426, 
2001.

Goldman, A. and Gillis, J. R.: Line parameters and line-by-line calculations for molecules of atmospheric interest. Technical report, Dep. of Physics, Univ. of Denver, CO, 1984.

Goldman, A., Murcray, F. H., Murcray, D. G., and Rinsland, C. P.: A search for formic acid in the upper troposphere: a tentative identification of the $1105 \mathrm{~cm}^{-1} v_{6}$ Q branch in high-resolution balloon-borne solar absorption spectra, Geophys. Res. Lett., 11, 307-310, 1984

González Abad, G., Bernath, P. F., Boone, C. D., McLeod, S. D., Manney, G. L., and Toon, G. C.: Global distribution of upper tropospheric formic acid from the ACE-FTS, Atmos. Chem. Phys., 9, 8039-8047, doi:10.5194/acp-9-8039-2009, 2009.

Grutter, M., Glatthor, N., Stiller, G. P., Fischer, H., Grabowski, U., Höpfner, M., Kellmann, S., Linden, A., and von Clarmann, T.: Global distribution and variability of formic acid as observed by MIPAS-ENVISAT, J. Geophys. Res., 115, D10303, doi:10.1029/2009JD012980, 2010.

Hahn, C. J., Merrill, J. T., and Mendonca, B. G.: Meteorological influences during MLOPEX, J. Geophys. Res., 97, 10291-10309, 1992.

Hartmann, W. R., Andreae, M. O., and Helas, G.: Measurements of organic acids over central Germany, Atmos. Environ., 23, 1531$1533,1989$.

Hartmann, W. R., Santana, M., Hermoso, M., Andreae, M. O., and Sanhueza, E.: Diurnal cycles of formic and acetic acids in the northern part of the Guyana shield, Venezuela, J. Atmos Chem., 13, 63-72, 1991.

Hocking, W. H.: The other rotamer of formic acid, cis-HCOOH, Z. Natur Forschung Serie A, Nr. 142, 1113-1121, 1976.

Irion, F. W., Gunson, M. R., Toon, G. C., Brown, L. R., Chang, A. Y., Eldering, A., Mahieu, E., Manney, G. L., Michelsen, H. A., Moyer, E. J., Newchurch, M. J., Osterman, G. B., Rinsland, C. P., Salawitch, R. J., Sen, B., Yung, Y. L., and Zander, R.: Atmospheric Trace Molecule Spectroscopy Experiment (ATMOS) version 3 data retrievals, Appl. Opt., 41(33), 6968-6979, 2002.

Ito, A., Sillman, S., and Penner, J. E.: Effects of additional nonmethane volatile organic compounds, organic nitrates, and direct emissions of oxygenated organic species on global tropospheric chemistry, J. Geophys. Res., 112, D06309, doi:10.1029/2005JD006556, 2007.

Jaeglé, L., Jacob, D. J., Brune, W. H., Faloona, I., Tan, D., Heikes, B. G., Kondo, Y., Sachse, G. W., Anderson, B., Gregory, G. L., Singh, H. B., Pueschel, R., Ferry, G., Blake, D. R., and Shetter, R. E.: Photochemistry of $\mathrm{HO}_{\mathrm{x}}$ in the upper troposphere at northern midlatitudes, J. Gepohys. Res., 105, 3877-3892, 2000.

Kajii, Y., Akimoto, H., Komazaki, Y., Tanaka, S., Mukai, H., Murano, K., and Merrill, J. T.: Long-range transport of ozone, carbon monoxide, and acidic trace gases at Oki Island, Japan, during PEM-WEST/PEACAMPOT B campaign, J. Geophys. Res., 102, 28637-28649, 1997.

Kanakidou, M. and Crutzen, P. J.: The photochemical source of carbon monoxide: importance, uncertainties and feedbacks, Chemosph. Global Change Sci., 1, 91-109, 1999.

Keene, W.C., and Galloway, J.N.: The biogeochemical cycling of formic and acetic acids through the troposphere: An overview of current understanding, Tellus, Ser. B, 40, 322-344, 1988.

Keene, W. C., Talbot, R. W., Andreae, M. O., Beecher, K., Berresheim, H., Castro, M., Farmer, J. C., Galloway, J. N.,
Hoffman, M. R., Li, S.-M., Maben, J. R., Munger, J. W., Norton, R. B., Pszenny, A. A. P., Puxbaum, H., Westberg, H., and Winiwarter, W.: An intercomparison of measurement systems for vapour- and particulate-phase concentrations of formic and acetic acids, J. Geophys. Res., 94, 6457-6472, 1989.

Kesselmeier, J. and Staudt, M.: Biogenic volatile organic compounds (VOC): An overview on emission, physiology and ecology, J. Atmos. Chem., 33, 23-88, 1999.

Khare, P., Kumar, N., Kumari, K. M., and Srivastava, S. S.: Atmospheric formic and acetic acids: an overview, Rev. Geophys., 37, 227-248, 1999.

Khwaja, H. A.: Atmospheric concentration of carboxylic acids and related compounds at a semi-rural site, Atmos. Environ., 29, 127-139, 1995.

Klemm, O., Talbot, R. W., Fitzgerald, D. R., Klemm, K. I., and Lefer, B. L.: Low to middle tropospheric profiles and biosphere/troposphere fluxes of acidic gases in the summertime Canadian taiga, J. Geophys. Res., 99, 1687-1698, 1994.

Legrand, M., Preunkert, S., Wagenbach, D., Cachier, H., and Puxbaum, H.: A historical record of formate and acetate from a high-elevation Alpine glacier: implications for their natural versus anthropogenic budgets at the European scale, J. Geophys. Res., 108(D24), 4788, doi:10.1029/2003JD003594, 2003.

Legrand, M., Preunkert, S., Jourdan, B., and Aumont, B.: Yearround records of gas and particulate formic and acetic acids in the boundary layer at Dumont d'Urville, coastal Antarctic, J. Geophys. Res., 109, D06313, doi:10.1029/2003JD003786, 2004

Liu, S. C., McAfee, J. R., and Cicerone, R. J.: Radon 222 and tropospheric vertical transport, J. Geophys. Res., 89, 7291-7297, 1984.

Mahieu, E., Zander, R., Demoulin, P., De Mazière, M., Mélen, F., Servais, C., Roland, G., Delbouille, L., Poels, J., and Blomme, R.: Fifteen years-trend characteristics of key stratospheric constituents monitored by FTIR above the Jungfraujoch, in: Harris, N. R. P., Guirlet, M., Amanatidis, G. T., editors of Proc of the Fifth European Symposium on Stratospheric Ozone, 27 September-1 October 1999, St. Jean de Luz, France. Air Pollution Research Report 73, 99-102, 2000.

Mahieu, E., Servais, C., Duchatelet, P., Zander, R., Demoulin, P., De Mazière, M., Senten, C., Walker, K. A., Boone, C. D., Rinsland, C. P., and Bernath, P.: Optimisation of retrieval strategies using Jungfraujoch high-resolution FTIR observations for longterm trend studies and satellite validation, in: Observing Tropospheric Trace Constituents from Space, ACCENT-TROPOSAT-2 in 2006-7, edited by: J. Burrows and P. Borrell, 280-285, 2007.

Meier, A., Toon, G. C., Rinsland, C. P., Goldman, A., and Hase, F.: Spectroscopic Atlas of atmospheric Microwindows in the middle-infrared. IRF Technical Report 048, ISSN 0284-1738, Printed by Swedish Institute of Space Physics, Kiruna, Sweden, 2004.

Migeotte, M. V., Neven, L., and Swensson, J.: The Solar Spectrum from 2.8 to 23.7 Microns -Part 1: Photometric atlas. Mém. S. R. Sci. Liège; Special Vol. 1, 1956.

Moody, J. L., Pszenny, A. A. P., Gaudry, A., Keene, W. C., Galloway, J. N., and Polian, G.: Precipitation composition and its variability in the Southern Indian ocean: Amsterdam island, 1980-1987, J. Geophys. Res., 96, 20769-20786, 1991.

Nazarov, L. E., Kuzenkov, A. F., Malakhov, S. G., Volokitina, L. A., Gaziyev, Ya. I., and Vasil'yev, A. S.: Radioactive 
aerosol distribution in the middle and upper troposphere over the USSR in 1963-1968, J. Geophys. Res., 75, 3575-3588, doi:10,1029/jc075i018p03575, 1970.

Norton, R. B.: Measurements of gas phase formic and acetic acids at the Mauna Loa Observatory, Hawaii, during the Mauna Loa Observatory Photochemistry Experiment 1988, J. Geophys. Res., 97, 10389-10393, 1992.

Notholt, J., Cappellani, F., Roesdahl, H., and Restelli, G.: Absolute infrared band intensities and air broadening coefficients for spectroscopic measurements of formic acid in air, Spectrochim. Acta-Part A, 47, 477-483, 1991.

Perrin, A., Rinsland, C. P., and Goldman, A.: Spectral parameters for the $v_{6}$ region of $\mathrm{HCOOH}$ and the measurement in the infrared tropospheric spectrum, J. Geophys. Res, 104, 1866118666, 1999.

Perrin , A. and Vander Auwera, J.: An improved database for the 9 micron region of the formic acid spectrum, J.Quant. Spectrosc. Radiat. Transfer, 108, 363-370, 2007.

Poisson, N., Kanakidou, M., and Crutzen, P. J.: Impact of nonmethane hydrocarbons on tropospheric chemistry and oxidizing power of the global troposphere: 3-dimensional modelling results, J. Atmos. Chem., 36, 157-230, 2000.

Pougatchev, N. S., Connor, B. J., and Rinsland, C. P.: Infrared measurements of the ozone vertical distribution above Kitt Peak, J. Geophys. Res., 100, 16689-16697, 1995.

Prospero, J. M., Savoie, D. L., Ness, R. T., Duce, R. A., and Merrill, J.: Particulate sulphate and nitrate in the boundary layer over the North Pacific Ocean, J. Geophys. Res., 90, 10586-10596, 1985.

Pszenny, A. A. P., Puxbaum, H., Westberg, H., and Winiwarter, W.: An intercomparison of measurement systems for vapor- and particulate-phase concentrations of formic and acetic acids, J. Geophys. Res., 94, 6457-6472, 1989.

Puxbaum, H., Rosenberg, C., Gregori, M., Lanzerstorfer, C., Ober, E., and Winiwarter, W.: Atmospheric concentrations of formic and acetic acids and related compounds in Eastern and Northern Austria, Atmos. Environ., 22, 2841-2850, 1988.

Reiner, T., Möhler, O., and Arnold, F.: Measurements of acetone, acetic acid, and formic acid in the northern midlatitude upper troposphere and lower stratosphere, J. Geophys. Res., 104, 1394313952, 1999.

Remedios, J. J., Allen, G., Waterfall, A. M., Oelhaf, H., Kleinert, A., and Moore, D. P.: Detection of organic compound signatures in infra-red, limb emission spectra observed by the MIPASB2 balloon instrument, Atmos. Chem. Phys., 7, 1599-1613, doi:10.5194/acp-7-1599-2007, 2007.

Rinsland, C. P., Jones, N. B., Connor, B. J., Logan, J. A., Pougatchev, N. S., Goldman, A., Murcray, F. J., Stephen, T. M., Pine, A. S., Zander, R., Mahieu, E., and Demoulin, P.: Northern and Southern Hemisphere ground-based infrared spectroscopic measurements of tropospheric carbon monoxide and ethane, J. Geophys. Res., 103, 28197-28217, 1998.

Rinsland, C. P., Mahieu, E., Zander, R., Goldman, A., Wood, S., and Chiou, L. S.: Free Tropospheric Measurements of Formic Acid (HCOOH) from Infrared Ground-Based Solar Absorption Spectra: Retrieval Approach, Evidence for a Seasonal Cycle, and Comparison with Model Calculations, J. Geophys. Res., 109, D1803, doi:10.1029/2004JD004917, 2004.

Rinsland, C. P., Boone, C. D., Bernath, P. F., Mahieu, E., Zander, R., Dufour, G., Clerbaux, C., Turquety, S., Chiou, L., Mc-
Connell, J. C., Neary, L., and Kaminsky, J. W.: First space-based observations of formic acid $(\mathrm{HCOOH})$ : Atmospheric Chemistry Experiment austral spring 2004 and 2005 Southern Hemisphere tropical-mid-latitude upper tropospheric measurements, Geophys. Res. Lett., 33, L23804, doi:10.1029/2006GL027128, 2006.

Rinsland, C. P., Turquety, S., Clerbaux, C., Dufour, G., Coheur, P.-F., Boone, C. D., Bernath, P. F., and Chiou, L. S.: Satellite boreal measurements over Alaska and Canada during June-July 2004: Simultaneous measurements of upper tropospheric $\mathrm{CO}, \mathrm{C}_{2} \mathrm{H}_{6}, \mathrm{HCN}, \mathrm{CH}_{3} \mathrm{Cl}, \mathrm{CH}_{4}, \mathrm{C}_{2} \mathrm{H}_{2}, \mathrm{CH}_{3} \mathrm{OH}$, $\mathrm{HCOOH}, \mathrm{OCS}$, and $\mathrm{SF}_{6}$, Global Biogeochem. Cy., 21, GB3008, doi:10.1029/2006GB002795, 2007.

Rodgers, C. D.: Retrieval of atmospheric temperature and composition from remote measurements of thermal radiation, Rev. Geophys., 14, 609-624, 1976.

Rothman, L. S., Barbe, A., Benner, D. C., Brown, L. R., CamyPeyret, C., Carleer, M. R., Chance, K. V., Clerbaux, C., Devi, V. M., Fayt, A., Flaud, J.-M., Gamache, R. R., Goldman, A., Jacquemart, D., Jucks, K. W., Lafferty, W. J., Mandin, J.-Y., Massie, S. T., Nemtchinov, V., Newnham, D. A., Perrin, A., Rinsland, C. P., Schroeder, J., Smith, J., Smith, M. A. H., Tang, K., Toth, R. A., Vander Auwera, J., Varanasi, P., and Yoshino, K.: The HITRAN molecular spectroscopic database: edition of 2000 Including Updates through 2001, J. Quant. Spectrosc. Radiat. Transfer, 82, 5-44, 2003.

Rothman, L. S., Jacquemart, D., Barbe, A., Chris Benner, D., Birk, M., Brown, L. R., Carleer, M. R., Chackerian Jr., C., Chance, K., Coudert, L. H., Dana, V., Devi, V .M., Flaud, J.-M., Gamache, R. R., Goldman, A., Hartmann, J.-M., Jucks, K. W., Maki, A. G., Mandin, J.-Y., Massie, S. T., Orphal, J., Perrin, A., Rinsland, C. P., Smith, M. A. H., Tennyson, J., Tolchenov, R. N., Toth, R. A., Vander Auwera, J., Varanasi, P., and Wagner, G.: The HITRAN 2004 molecular spectroscopic database, J. Quant. Spectosc. Radiat. Transfer, 96, 139-204, 2005.

Rothman, L. S., Gordon, I. E., Barbe, A., Benner, D. C., Bernath, B. E., Birk, M., Boudon, V., Brown, L. R., Campargue, A., Champion, J. P., Chance, K., Coudert, L. H., Dana, V., Devi, V. M., Fally, S., Flaud, J.-M., Gamache, R. R., Goldman, A., Jacquemart, D., Kleiner, I., Lacome, N., Lafferty, W. J., Mandin, J. Y., Massie, S. T., Mikhailenko, S. N., Miller, C. E., Moazzen-Ahmadi, N., Naumenko, O. V., Nikitin, A. V., Orphal, J., Perevalov, V. I., Perrin, A., Predoi-Cross, A., Rinsland, C. P., Rotger, M., Simeckova, M., Smith, M. A. H., Sung, K., Tashkun, S. A., Tennyson, J., Toth, R. A., Vandaele, A. C., and Vander Auwera, J.: The HITRAN 2008 molecular spectroscopy database, J. Quant. Spectrosc. Radiat. Transfer, 110, 533-572, doi:10.1016/jqsrt.2009.02.013, 2009.

Sanhueza, E., Santana, M., Trapp, D., Serves, C., Figueroga, L., Romero, R., Rondon, A., and Donoso, L.: Field measurement evidences for an atmospheric chemical source of formic and acetic acids in the tropics, Geophys. Res. Lett., 23, 1045-1048, 1996.

Shephard, M. W., Goldman, A., Clough, S. A., and Mlawer, E. J.: Spectroscopic improvements providing evidence of formic acid in AERI-LBLRTM validation spectra, J. Quant. Spectrosc. Radiat. Transfer, 82, 383-390, 2003.

Singh, H., Chen, Y., Tabazadeh, A., Fukui, Y., Bey, I., Yantosca, R., Jacob, D., Arnold, F., Wohlfrom, K., Atlas, E., Flocke, F., Blake, D., Blake, N., Heikes, B., Snow, J., Talbot, R., Gre- 
gory, G., Sachse, G., Vay, S., and Kondo, Y.: Distribution and fate of selected oxygenated organic species in the troposphere and lower stratosphere over the Atlantic, J. Geophys. Res., 105, 3795-3805, 2000.

Talbot, R. W., Beecher, K. M., Harris, R. C., Browell, E .V., and Coffer, W. R.: Atmospheric geochemistry of formic and acetic acids at a midlatitude temperate site, J. Geophys. Res., 93, 16381652, 1988.

Talbot, R. W., Andreae, M. O., Berresheim, H., Jacob, D. J., and Beecher, K. M.: Sources and sinks of formic, acetic and pyruvic acids over central Amazonia - Part 2 - Wet season, J. Geophys. Res., 95, 16799-16811, 1990.

Talbot, R. W., Mosher, R. W., Heikes, B. G., Jacobs, D. J., Munger, J. W., Daube, B. C., Keene, W. C., Maben, J. R., and Artz, R. S.: Carboxylic acids in the rural continental atmosphere over the eastern United States during the Shenandoah Cloud and Photochemistry Experiment, J. Geophys. Res., 100, 9335-9343, 1995.

Talbot, R. W., Dibb, J. E., Klemm, K. I., Bradshaw, J. D., Sandholm, S. T., Blake, D. R., Sachse, G. W., Collins, J., Heikes, B. G., Gregory, G. L., Anderson, B. E., Singh, H. B., Thornton, D. C., and Merrill, J. T.: Chemical characteristics of continental outflow from Asia to the troposphere over the Western Pacific Ocean during September-October 1991: results from PEM-West A, J. Geophys. Res., 101, 1713-1725, 1996a.

Talbot, R. W., Bradshaw, J. D., Sandholm, S. T., Smyth, S., Blake, D. R., Blake, N. J., Sachse, G. W., Collins, J. E., Heikes, B. G., Anderson, B. E., Gregory, G. L., Singh, H. B., Singer, B. L., and Bachmeier, A. S.: Chemical characteristics of continental outflow over the tropical South Atlantic Ocean from Brazil and Africa, J. Geophys. Res., 101, 24187-24202, 1996 b.

Talbot, R. W., Dibb, J. E., Lefer, B. L., Bradshaw, J. D., Sandholm, S. T., Blake, D. R., Blake, N. J., Sachse, G. W., Collins, J. E., Jr., Heikes, B. G., Merrill, J. T., Gregory, G. L., Anderson, B. E., Singh, H. B., Thornton, D. C., Bandy, A. R., and Pueschel, R. F.: Chemical characteristics of continental outflow from Asia to the troposphere over the Western Pacific Ocean during FebruaryMarch 1994: results from PEM-West B, J. Geophys. Res., 102, 28255-28274, 1997a.
Talbot, R. W., Dibb, J. E., Lefer, B. L., Scheuer, E. M., Bradshaw, J. D., Sandholm, R. T., Smyth, S., Blake, D. R., Blake, N. J., Sachse, G. W., Collins, J. E., and Gregory, G. L.: Large-scale distribution of tropospheric nitric, formic, and acetic acids over the Western Pacific basin during wintertime, J. Geophys. Res., 102, 28303-28313, $1997 \mathrm{~b}$.

Toon, G. C.: The JPL MKIV interferometer, Optics \& Photonics News, 2(10), 19-21, 1991.

Vander Auwera, J., Didriche, K., Perrin, A., Keller, F., and Flaud, J.-M.: Absolute intensities in the $v_{6}$ band of trans-formic acid. Paper RB11 presented at the $59^{\text {th }}$ International Symposium on Molecular Spectroscopy, Ohio State Univ., Columbus, Ohio, 2125 June, 2004.

Vander Auwera, J., Didriche, K., Perrin, A., and Keller, F.: Absolute line intensities for formic acid and dissociation constant of the dimer, J. Chem. Phys., 126, 124311, doi:10.1063/1.2712439, 2007.

Von Kuhlmann, R., Lawrence, G., Crutzen, P. J., and Rasch, P. J.: A model for studies of tropospheric ozone and nonmethane hydrocarbons: model evaluation of ozone-related species, J. Geohys. Res., 108(D23), 4729, doi:10.1029/2002JD003348, 2003.

Zander, R., Mahieu, E., Demoulin, P., Duchatelet, P., Servais, C., Roland, G., Delbouille, L., De Mazière, M., and Rinsland, C. P.: Evolution of a dozen non- $\mathrm{CO}_{2}$ greenhouse gases above Central Europe since the mid-1980s, Environmental Sciences, 2(23), 295-303, June-September, 2005.

Zander, R., Mahieu, E., Demoulin, P., Duchatelet, P., Roland, G., Servais, C., De Mazière, M., Reimann, S., and Rinsland, C. P.: Our changing atmosphere: evidence based on long-term infrared solar observations at the Jungfraujoch since 1950, Sci. Total Environ., 391, 184-195, 2008. 